\title{
Improved Parameterization of Ice Particle Size Distributions Using Uncorrelated Mass Spectrum Parameters: Results from GCPEx
}

\author{
PALOMA BORQUE \\ Department of Atmospheric Sciences, University of Illinois at Urbana-Champaign, Urbana, Illinois \\ KIRSTIN J. HARNOS \\ NOAA/Climate Prediction Center, College Park, Maryland \\ STEPHEN W. NESBITT \\ Department of Atmospheric Sciences, University of Illinois at Urbana-Champaign, Urbana, Illinois
}

GREG M. MCFARQUHAR

Cooperative Institute of Mesoscale Meteorological Studies and School of Meteorology, University of Oklahoma, Norman, Oklahoma

(Manuscript received 1 August 2018, in final form 18 February 2019)

\begin{abstract}
Satellite retrieval algorithms and model microphysical parameterizations require guidance from observations to improve the representation of ice-phase microphysical quantities and processes. Here, a parameterization for ice-phase particle size distributions (PSDs) is developed using in situ measurements of cloud microphysical properties collected during the Global Precipitation Measurement (GPM) Cold-Season Precipitation Experiment (GCPEx). This parameterization takes advantage of the relation between the gamma-shape parameter $\mu$ and the mass-weighted mean diameter $D_{m}$ of the ice-phase PSD sampled during GCPEx. The retrieval of effective reflectivity $Z_{e}$ and ice water content (IWC) from the reconstructed PSD using the $\mu-D_{m}$ relationship was tested with independent measurements of $Z_{e}$ and IWC and overall leads to a mean error of $8 \%$ in both variables. This represents an improvement when compared with errors using the Field et al. parameterization of $10 \%$ in IWC and $37 \%$ in $Z_{e}$. Current radar precipitation retrieval algorithms from GPM assume that the PSD follows a gamma distribution with $\mu=3$. This assumption leads to a mean overestimation of $5 \%$ in the retrieved $Z_{e}$, whereas applying the $\mu-D_{m}$ relationship found here reduces this bias to an overestimation of less than $1 \%$. Proper selection of the $a$ and $b$ coefficients in the mass-dimension relationship is also of crucial importance for retrievals. An inappropriate selection of $a$ and $b$, even from values observed in previous studies in similar environments and cloud types, can lead to more than $100 \%$ bias in IWC and $Z_{e}$ for the ice-phase particles analyzed here.
\end{abstract}

\section{Introduction}

Precipitation is a key component of Earth's water and energy cycles with direct consequences for life on Earth. The understanding of precipitation processes has a variety of implications on local and global scales including the accurate quantification of freshwater supply and the monitoring of extreme precipitation events. Models

Corresponding author: Paloma Borque, paloma@illinois.edu and observations of ice-phase precipitation, used to address these challenges, require assumptions of the characteristics of the particle size distribution (PSD) to perform accurate simulations and retrievals. In this work, a new parameterization for the ice-phase PSD based on aircraft measurements collected during the Global Precipitation Measurement (GPM) Cold-Season Precipitation Experiment (GCPEx) is developed. This new parameterization leverages the uncorrelated mass parameter PSD estimation technique developed by 
Williams et al. (2014), as described below to eliminate a free parameter in assumed PSD characteristics, which can provide reduced uncertainties in ice-phase microphysical models and retrievals compared with currently used schema.

One key application of an ice-phase PSD parameterization is for spaceborne active and passive ice cloud retrievals. The GPM (Hou et al. 2014; SkofronickJackson et al. 2017) Core Observatory satellite was launched on 28 February 2014 by the National Aeronautics and Space Administration (NASA) and Japanese Aerospace Exploration Agency as a follow-up to the successful Tropical Rainfall Measuring Mission (TRMM; Kummerow et al. 1998). The dual-frequency precipitation radar (DPR) aboard the GPM Core Observatory satellite consists of a $\mathrm{Ku}$-band radar operating at $13.6 \mathrm{GHz}$ with a minimum detectable equivalent reflectivity factor of $12-14 \mathrm{dBZ}$ (or $0.5 \mathrm{~mm} \mathrm{~h}^{-1}$ ) and a Ka-band radar operating at $35.5 \mathrm{GHz}$ with a minimum detectable reflectivity of $12 \mathrm{dBZ}$ (or $0.2 \mathrm{~mm} \mathrm{~h}^{-1}$; Toyoshima et al. 2015). The increased sensitivity and the addition of the Ka-band frequency represents a new capability of GPM over TRMM to measure snowfall and light precipitation from a space-based perspective. Further, the sample of precipitation with both DPR frequencies in an overlapping swath can lead to quantitative estimates of PSD characteristics that can be used to improve the associated GPM retrieval algorithms (Hou et al. 2014). This can be achieved by a better determination of the PSD-derived physical quantities such as ice water content (IWC) and effective reflectivity $Z_{e}$.

In current GPM algorithms, PSDs are assumed to follow gamma distributions with three unknown mathematical parameters: the intercept $N_{0}$, the shape $\mu$, and the slope $\lambda$ (e.g., Ulbrich 1983; Seto et al. 2013; Williams et al. 2014; Wu and McFarquhar 2018). Given two independent measurements and an assumption or a constraint on the third parameter, the PSD can be retrieved. There has been extensive work on the constraint of one of the three gamma parameters both from a ground-based radar perspective (Zhang et al. 2001, 2003, 2006; Moisseev and Chandrasekar 2007; Bringi and Chandrasekar 2001; Delanoë et al. 2014) and as part of satellite retrieval algorithms (Seto et al. 2013; Williams et al. 2014; Grecu et al. 2011; Liao et al. 2014). Currently, the DPR retrieval algorithm provides two measurements $\left[Z_{e}\right.$ and dual-frequency ratio (DFR)] and assumes a constant value of $\mu=3$ (Seto et al. 2013). Recent studies show success in reducing biases in the algorithms by estimating uncorrelated mass parameters in rainfall events (Williams et al. 2014; Liao et al. 2014). In particular, Williams et al. (2014) avoided mathematical artifacts by developing joint probability distribution functions of statistically independent PSD attributes for the raindrop mass spectrum.

Beyond satellite retrieval needs of parameterizing the PSD in ice-phase clouds, multiscale numerical models need a priori assumptions of ice and snow hydrometeor species within bulk and bin microphysical parameterizations. At this time, most single-moment PSD schemes (e.g., Lin et al. 1983; Hong et al. 2004; Thompson et al. 2008; Lang et al. 2014) prescribe PSD characteristics with a fixed intercept and $\mu$ parameter (the latter value typically prescribed to be $\mu=0$, yielding an exponential size distribution), with a slope parameter that is a function of predicted hydrometeor mixing ratio. In most two-moment schemes, $\mu$ is usually assumed to be constant (e.g., Ferrier 1994; Meyers et al. 1997; Cohard and Pinty 2000; Morrison et al. 2009). However, others, such as the predicted particle properties (P3) scheme, use variable $\mu$ for ice particles but follow in situ observations of Heymsfield (2003) for tropical and midlatitude ice cloud particles, with $\mu$ limited to positive values below 6 (Morrison and Milbrandt 2015). Bin microphysics schemes have been developed more recently in an attempt to more accurately represent PSD characteristics in model simulations. However, the behavior of these schemes in ice-phase precipitation has only rarely been quantitatively evaluated (e.g., Naeger et al. 2017; Milbrandt and Yau 2005).

It is clear that satellite retrievals of ice-phase particles and model microphysical parameterizations are in need of guidance from in situ observations as a potential way forward to improve the representation of ice-phase microphysical processes. In this study, a catalog of in situ measurements collected during an intensive cold-season precipitation field campaign is used to evaluate the uncorrelated mass parameters approach to estimate ice-phase PSDs. Furthermore, a new PSD parameterization is introduced aiming to improve the consistency of ice-phase precipitation retrievals.

\section{Data}

GPM-Ground Validation (GV) campaigns collected precipitation measurements over the course of multiple field campaigns in an effort to mitigate the uncertainty in GPM retrieval algorithm assumptions, especially in precipitation regimes that were previously challenging to retrieval algorithms (Petersen and Schwaller 2008). Comparisons of precipitation products from CloudSat, Aqua, TRMM, and GPM show a clear disagreement in precipitation amounts 
at latitudes poleward of $30^{\circ}$. These discrepancies are most likely a result of different sensitivities of the sensors [CloudSat Cloud-Profiling Radar: $-27 \mathrm{dBZ}$, TRMM Precipitation Radar (PR): $18 \mathrm{dBZ}$, and GPM DPR: $12 \mathrm{dBZ}$ ) in conjunction with the majority of precipitation occurring in the form of snowfall and of light rainfall with shallow freezing levels and the inability of those satellite precipitation sensors to accurately detect and estimate precipitation in the regimes found there (L'Ecuyer et al. 2010; Tang et al. 2017; Casella et al. 2017). Differences among the various retrieval algorithms that determine the phase of precipitation could also play a role in these differences.

\section{a. Aircraft in situ data}

One of the overarching goals of GPM-GV is to characterize the ability of multifrequency active and passive microwave sensors to detect and estimate ice-phase precipitation rate. This effort entails numerous GPMspecific and joint-agency field campaigns with state of the art cloud and precipitation observational capabilities (e.g., polarimetric radars, wind profiler radars, rain gauges, disdrometers, and aircraft in situ observations). One such field campaign was GCPEx conducted in cooperation with Environment and Climate Change Canada (ECCC) and NASA in January-February of 2012 near Barrie, Ontario, Canada (Skofronick-Jackson et al. 2015). GCPEx collected in situ cloud microphysics and thermodynamic measurements using the University of North Dakota (UND) Cessna Citation II research aircraft (Delene and Poellot 2012). Aboard the Citation, the King probe was used to quantify the liquid water content (LWC), the Nevzorov probe (Korolev et al. 1998) was used to measure the LWC and total water content (TWC), and the Rosemount Icing Detector (RICE) was used to detect the presence of supercooled liquid water (Brown 1982). Baumgardner et al. (2017) and references therein describe the different in situ probes and measurements that are used to characterize the microphysical properties of ice clouds.

Two-dimensional cloud probe data from the UND Citation were processed by the System for Optical Array Probe Data Analysis (SODA) software developed by the National Center for Atmospheric Research. PSDs were obtained from a combination of observations from the Cloud Imaging Probe (CIP) and the High Volume Precipitation Spectrometer, version 3 (HVPS3). The CIP is an airborne particle spectrometer that nominally measures the size and shape of cloud particles from 25 to $1550 \mu \mathrm{m}$, and the HVPS 3 measures the size and shape of cloud particles from about $150 \mu \mathrm{m}$ to $19.2 \mathrm{~mm}$. Following Heymsfield et al. (2008), merged PSDs were constructed with the CIP data for particles with maximum dimension $D$ smaller than $1 \mathrm{~mm}$ and with the HVPS3 data for particles with $D>1 \mathrm{~mm}$. Particles with $D<$ $100 \mu \mathrm{m}$ were ignored because of uncertainties in the probe's sample area (e.g., Korolev and Field 2015; Field et al. 2006). Particle reconstruction for particles whose geometrical center was in the photodiode array was used to expand the sampling range of both the CIP and HVPS3 following the method described in Heymsfield and Parrish (1978). Antishattering tips and the algorithms described in McFarquhar et al. (2017) were used to remove shattered artifacts from the sampled PSDs. The use of the HVPS3, capable of measuring large aggregates, and the handling of shattered artifacts through improved probe design and software quality control diminished the source of error in the sampled particles and allows for an improved characterization of the PSD in comparison with previous studies (e.g., Field et al. 2007).

During 12 intensive observation periods (IOPs) in GCPEx, the UND Citation sampled a variety of winter precipitation systems, with the majority representing synoptically forced snowfall over southern Ontario in Canada. This study seeks to characterize the PSDs in exclusively ice-phase conditions. To achieve this, a technique has been implemented to only include data when the research aircraft sampled regions with purely ice particles, namely excluding times when liquid or mixed-phase conditions were present. Thus, in situ observations were only considered if they met the following three criteria: temperature $T<-2^{\circ} \mathrm{C}$, total particle total number concentration $>10^{3} \mathrm{~m}^{-3}$, and no changes in the voltage measured by the RICE above or below one standard deviation of the median voltage of the flight leg. Although other studies apply more sophisticated phase detection schemes to delineate ice, mixed phase, and liquid clouds (e.g., Cober et al. 2001; McFarquhar et al. 2007; Jackson et al. 2012), the approach used here proved to be sufficient to eliminate cases where liquid was present in the sampled volume. Visual inspection of the high-resolution Cloud Particle Imager (CPI) imagery confirmed that periods in which liquid drops large enough to be observed by the CPI were present are well correlated with period of variations in the observed RICE output, thus confirming that the aforementioned exclusion criteria is capable of detecting the presence of supercooled liquid water particles larger than approximately $35 \mu \mathrm{m}$ (McFarquhar et al. 2013). Furthermore, the RICE criterion is a very conservative condition and it could filter out time periods in which the presence of super cooled liquid drops is not visible in CPI imagery, or when the RICE probe is going in the reheating cycle, provided the temperature was less than about $-2^{\circ} \mathrm{C}$. However, it will achieve its purpose of 

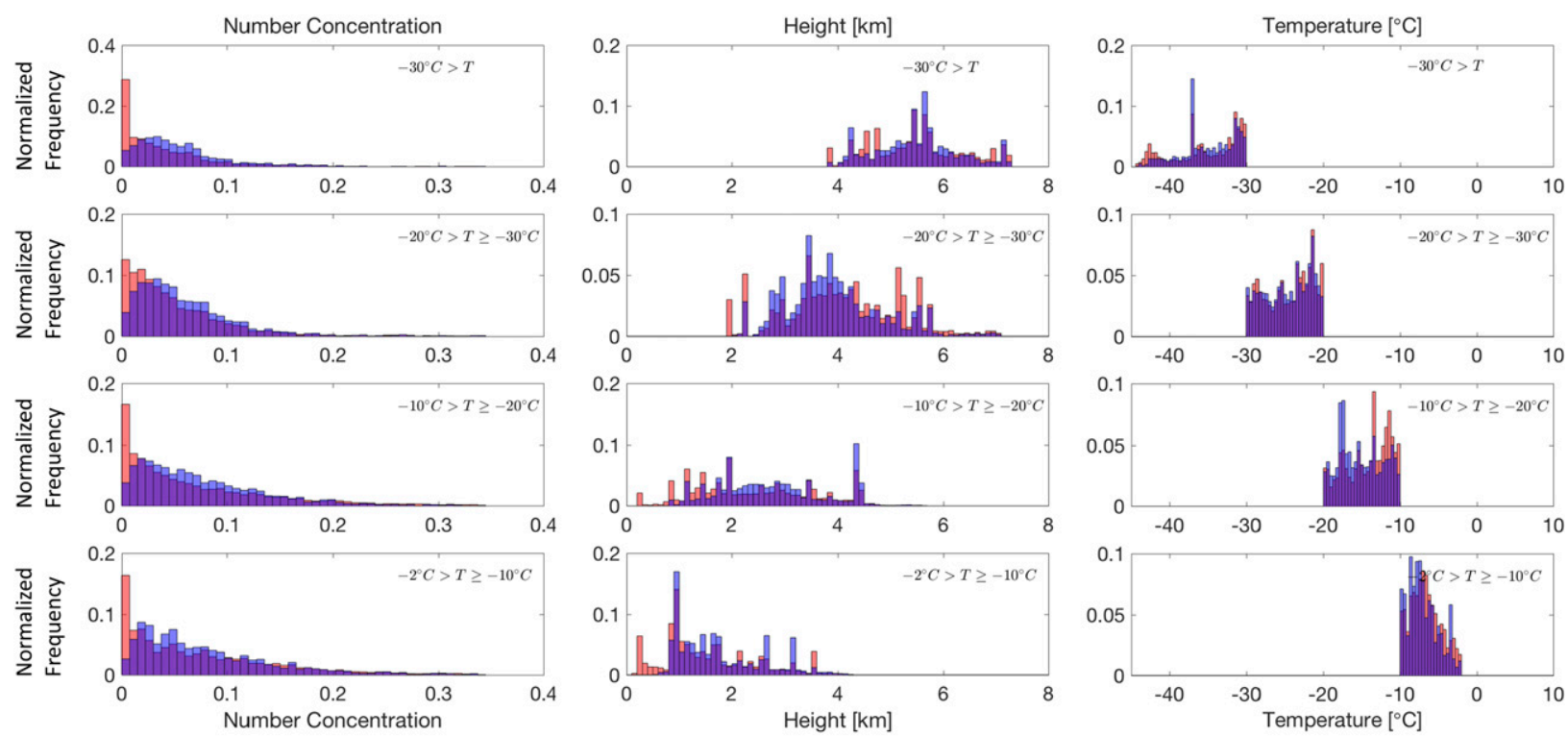

All in-situ data

Ice phase clouds

FIG. 1. PDF of (left) number concentration, (center) height, and (right) temperature for different temperatures ranging from below $-30^{\circ} \mathrm{C}$ to $-2^{\circ} \mathrm{C}$, increasing every $10^{\circ} \mathrm{C}$, for all of the observations collected by the UND Citation (red) and for the ice-phase-only cases analyzed in this work (blue). Distributions for temperature for which the absence of liquid water could not be verified (i.e.: $T>-2^{\circ} \mathrm{C}$ ) are not shown.

retaining mostly periods of only ice-phase particles in the sample volume.

To describe the environmental and PSD characteristics sampled in GCPEx as well as those that were subselected in only ice-phase conditions, Fig. 1 shows probability distribution functions (PDFs) of observed quantities for all flights. Observations were collected from about $500 \mathrm{~m}$ AGL to heights below $8 \mathrm{~km}$ for temperatures ranging from slightly above $0^{\circ} \mathrm{C}$ to below $-40^{\circ} \mathrm{C}$. Height distributions follow the expected inverse relation with temperature, and none of these variables show a clear preferred value as a function of specific temperature ranges (Fig. 1). It is important to note that restricting the analysis to ice-phase conditions implies that the TWC measured by the Nevzorov probe should be identical to the IWC.

\section{b. Radar measurements}

Ground-based radar observations were also an integral part of GCPEx; such observations are of fundamental importance to link the in situ measured particle properties to remotely sensed bulk characteristics. As part of GCPEx, ECCC's dual-polarization scanning C-band radar located in King City, Ontario, Canada, performed (in addition to their operational scanning) range-height indicator sector scans and plan position indicator scans (Hudak 2013). For some IOPs, the UND Citation flew in the coverage region of the King City radar, allowing for more than 3700 coincident (as defined in section 2c) 10-s averaged measurements between ground-based and in situ instrumentation. Following Marks et al. (2011), radar reflectivity data were quality controlled by removing points with copolar correlation coefficient $\rho_{\mathrm{HV}}<0.75$ and range standard deviation of differential phase $\Phi_{\mathrm{DP}}$ over a gate-centered window of $1.5 \mathrm{~km}>12^{\circ}$.

\section{c. In situ and ground-based data matching}

The volumes sampled by probes onboard the UND Citation and by the King City radar are not coincident. Therefore, it is necessary to determine what temporal and spatial separation can be tolerated to assume the in situ measurements as linked to a corresponding radar volume. In the present study, the volumes sampled by the King City Radar and the UND Citation were defined as collocated in time when the Citation was sampling within the start and end time of each 10-min volume coverage pattern. Once a collocated volume was defined a spatial matching algorithm between the radar volume and Citation observations was used. Points were weighted by constructing a collocated reflectivity along the aircraft track averaged in linear units $\left(\mathrm{mm}^{6} \mathrm{~m}^{-3}\right)$ using an eight-closest point Barnes (1964) interpolation technique as in Finlon et al. (2019). Reflectivities are weighted according to distance $r$ from the aircraft using $w_{i}=\exp \left(-r^{2} / \kappa^{2}\right)$, with weighting parameter $\kappa$ given a 
value of $500 \mathrm{~m}$. A sensitivity analysis of the radius of influence in the matching technique showed that varying $\kappa$ over selected values from $100 \mathrm{~m}$ to $1.5 \mathrm{~km}$ for all GCPEx flights only slightly changed the bias and root-mean-square differences of the matched radar reflectivities relative to the value of $\kappa$ used. Matched reflectivity values were biased on average by less than $0.3 \mathrm{dBZ}$ with a mean root mean squared difference of $1.2 \mathrm{~dB} Z$ for all radii tested except for radii less than $250 \mathrm{~m}$ (which was the radial gate spacing of the raw radar data).

\section{PSD reconstruction}

\section{a. Definitions of PSD parameters}

Particle size distributions are often assumed to follow a gamma-shaped distribution given by

$$
N(D)=N_{0} D^{\mu} e^{-\lambda D}
$$

where $N(D)$ is the number distribution function and $D$, $N_{0}, \mu$, and $\lambda$ are as defined above (e.g., Ulbrich 1983; Seto et al. 2013; Williams et al. 2014). Therefore, three parameters $\left(N_{0}, \mu\right.$, and $\left.\lambda\right)$ are needed to characterize a PSD when represented as a gamma function. A well-documented caveat with this PSD formulation is the statistical dependence among these parameters (e.g., Ulbrich 1983; Chandrasekar and Bringi 1987; Moisseev and Chandrasekar 2007; Williams et al. 2014; McFarquhar et al. 2015). Constraining one of the parameters, such as by introducing a $\mu-\lambda$ relationship, reduces the number of free parameters within the gamma PSD. Previous studies (e.g., Zhang et al. 2001, 2003) have shown that the application of such a relation between $\mu$ and $\lambda$ can improve rain-rate estimations. However, others (e.g., Atlas and Ulbrich 2006; Moisseev and Chandrasekar 2007; Zhang et al. 2003; Cao and Zhang 2009) have debated whether this statistical dependence can be used to discern physical properties or if it is a statistical artifact due to the initial assumption of the gamma size distribution. For liquid particles, the DPR algorithm avoids such assumptions by calculating the PSD with a normalized gamma function (Testud et al. 2001) in terms of $\mu$ and two physical quantities: the normalized intercept $N_{w}$ (which is a function of LWC) and the mass-weighted mean diameter $D_{m}$ (Chandrasekar et al. 2005; Seto et al. 2013), where

$$
N(D)=N_{w} \frac{6(\mu+b+1)^{(\mu+b+1)}}{4^{(b+1)} \Gamma(\mu+b+1)}\left(\frac{D}{D_{m}}\right)^{\mu} e^{-(\mu+b+1)\left(D / D_{m}\right)},
$$

with

$$
\begin{aligned}
& D_{m}=\frac{\int_{0}^{\infty} m N(D) D d D}{\int_{0}^{\infty} m N(D) d D} \quad \text { and } \\
& N_{w}=\frac{4^{b+1}}{\pi \rho_{w}}\left(\frac{\mathrm{LWC}}{D_{m}^{b+1}}\right) .
\end{aligned}
$$

Herein, $a$ and $b$ are the parameters of the power-law particle mass-dimension relation of the form $m=a D^{b}$ described in more detail in section 4. Delanoë et al. (2014) showed that by combining $N_{0}, D_{m}$, and a modified gamma function the IWC could be estimated with an absolute mean relative error smaller than $20 \%$. Current TRMM PR and DPR algorithms retrieve $N_{w}$ and $D_{m}$ given an assumption on $\mu$ (e.g., Meneghini et al. 1992; Zhang et al. 2001; Mardiana et al. 2004; Liao and Meneghini 2005; Munchak and Tokay 2008; Kumar et al. 2011; Grecu et al. 2011; Seto et al. 2013; Williams et al. 2014). In particular, current GPM version-5 algorithms assume $\mu$ to be constant and equal to 3 (Seto et al. 2013). However, the rain rates estimated from these retrieval algorithms are sensitive to $\mu$, and small changes in its value lead to large changes in precipitation estimates. For example, Grecu et al. (2011) showed that changing $\mu$ from 0 to 1 led to $15 \%$ differences in the estimations of precipitation water content, whereas Liao et al. (2014) showed that larger $\mu$ values (3, 6, and 10) lead to a relative bias of rain-rate estimates of larger than $10 \%$. Williams et al. (2014) proposed a method to parameterize gamma PSD characteristics by calculating a statistically independent $\mu-D_{m}$ constraint for the $\mu$ parameter. Their results showed that the rain-rate bias never exceeded $3.5 \%$ when the statistically independent $\mu-D_{m}$ constraint was applied. Our study expands the Williams et al. (2014) technique to ice particles, and thus, given the variable effective density of ice-phase particles, the coefficients of $a$ and $b$ in the mass-dimension relation must be considered. Therefore, expanding Eq. (3) leads to

$$
\begin{aligned}
D_{m}= & \frac{\int_{0}^{\infty} a D^{b} N(D) D d D}{\int_{0}^{\infty} a D^{b} N(D) d D}=\frac{\int_{0}^{\infty} D^{b+1} N(D) d D}{\int_{0}^{\infty} D^{b} N(D) d D} \\
\cong & \frac{\sum_{\min }^{D_{\max }} D^{b+1} N(D) \Delta D}{\sum_{D_{\min }}^{D_{\max }} D^{b} N(D) \Delta D}
\end{aligned}
$$



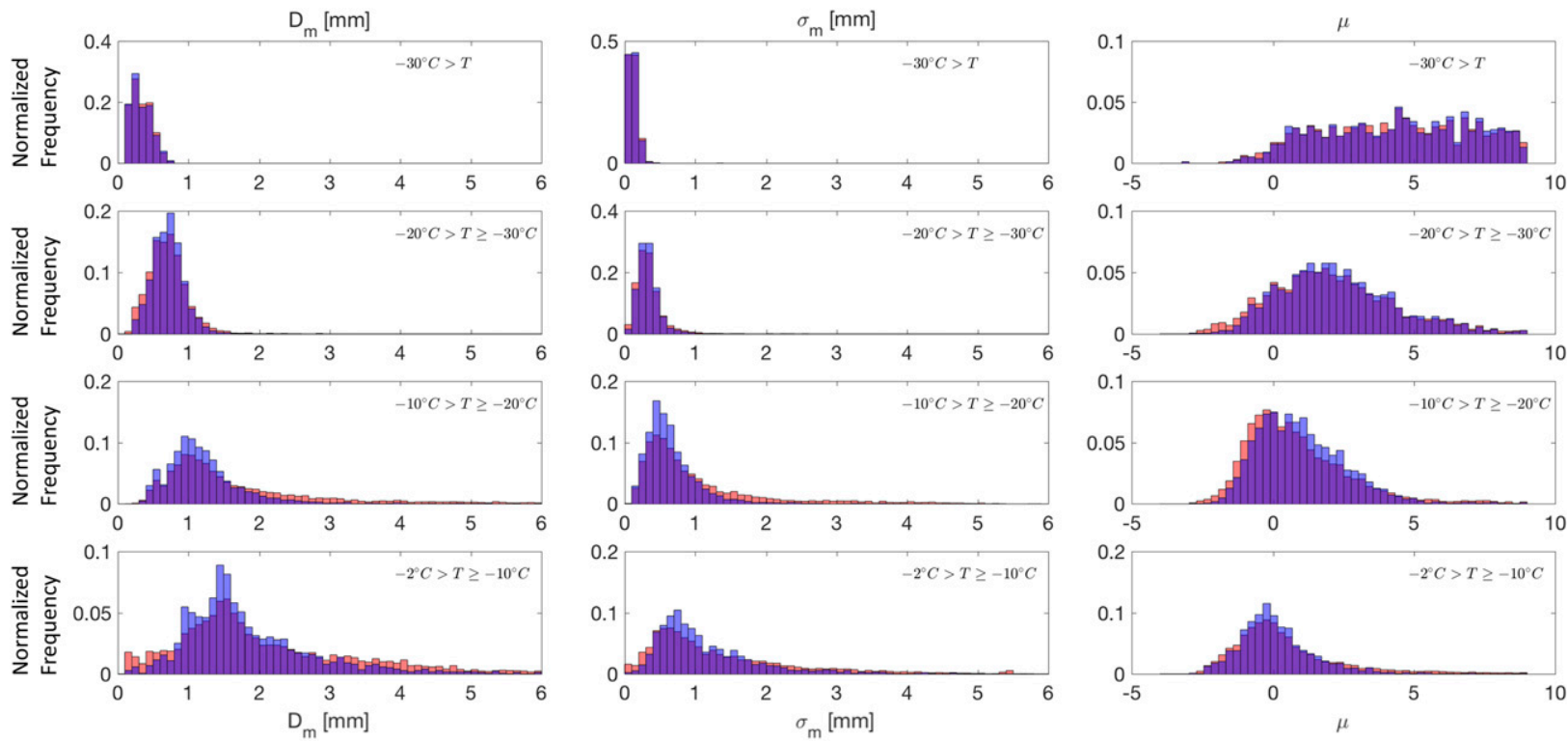

All in-situ data

Ice phase clouds

FIG. 2. As in Fig. 1, but for (left) $D_{m}$, (center) $\sigma_{m}$, and (right) $\mu$.

and the mass spectrum standard deviation $\sigma_{m}$, which physically represents the width of the PSD mass spectrum, is given by

$$
\begin{aligned}
\sigma_{m}^{2} & =\frac{\int_{0}^{\infty} m N(D)\left(D-D_{m}\right)^{2} d D}{\int_{0}^{\infty} m N(D) d D} \\
& =\frac{\int_{0}^{\infty} a D^{b} N(D)\left(D-D_{m}\right)^{2} d D}{\int_{0}^{\infty} a D^{b} N(D) d D} \\
& \cong \frac{\sum_{D_{\min }}^{D_{\max }} D^{b} N(D)\left(D-D_{m}\right)^{2} \Delta D}{\sum_{D_{\min }}^{D^{b}} D^{b} N(D) \Delta D},
\end{aligned}
$$

where $D_{\min }$ and $D_{\max }$ are the minimum and maximum dimensions of measured ice particles, respectively, and $\Delta D$ is the width of the size bin.

Combining Eqs. (5) and (6) leads to

$$
\mu=\left(D_{m}^{2} / \sigma_{m}^{2}\right)-(b+1) .
$$

Following Williams et al. (2014), a statistically independent parameter $\sigma_{m}^{\prime}$ can be defined as

$$
\sigma_{m}^{\prime}=\sigma_{m} / D_{m}^{b_{m}}
$$

where $b_{m}$ is adjusted until the Pearson correlation coefficient between $\sigma_{m}$ and $D_{m}$ is 0 (Haddad et al. 1996; Williams et al. 2014). This leads to the following statistically independent relationship for $\mu$ :

$$
\mu=\left[D_{m}^{2\left(1-b_{m}\right)} / \sigma_{m}^{\prime 2}\right]-(b+1) .
$$

The parameters of the $m-D$ relationship used in this work $\left(a=3.59 \times 10^{-3} \mathrm{~g} \mathrm{~cm}^{-2.1}\right.$ and $\left.b=2.1\right)$ correspond to the values found by Heymsfield et al. (2010) for observations analyzed in a similar region to where GCPEx took place [Alliance Icing Research Study (AIRS) in Toronto, Ontario, Canada, and the Canadian CloudSat/Cloud-Aerosol Lidar and Infrared Pathfinder Satellite Observations (CALIPSO) Validation Programme (C3VP) near Barrie].

Figure 2 shows PDFs of $D_{m}, \sigma_{m}$, and $\mu$ derived from the in situ observations for all of the flights that took place during GCPEx. The properties have different distributions depending on temperature (Fig. 2). There is a noticeable increase in $D_{m}$ as temperature increases, from a median of around $0.25 \mathrm{~mm}$ for temperatures lower than $-30^{\circ} \mathrm{C}$ to $1.5 \mathrm{~mm}$ in the interval from $-2^{\circ}$ to $-10^{\circ} \mathrm{C}$. The PSD becomes narrower as temperature decreases (with a normal distribution of $\sigma_{m}$ centered at $0.8 \mathrm{~mm}$ for $-2^{\circ}<T<-10^{\circ} \mathrm{C}$ to $\sigma_{m}$ close to zero for $T<30^{\circ} \mathrm{C}$ ). The shape parameter $\mu$ is centered around zero for temperatures between $-2^{\circ}$ and $-20^{\circ} \mathrm{C}$ but shifts toward larger values as temperature decreases such that for temperatures between $-20^{\circ}$ and $-30^{\circ} \mathrm{C}$ it is centered 



FIG. 3. Joint frequency of occurrence of (a) $\sigma_{m}$ and (b) $\mu$ as a function $D_{m}$ for the entire ice-phase dataset. (c),(d) As in (a) and (b), but using the melted equivalent diameter. The statistically independent relationship between the different variables for ice and snow cases from GCPEx in situ observations (red line) and for rainfall from Williams et al. (2014) (black line) and their equations are also shown.

at $\mu=2$. The width of the $\mu$ PDF also increases with decreasing temperature, from a narrow distribution at the highest temperature to a very broad distribution for temperatures below $-30^{\circ} \mathrm{C}$ (Fig. 2). It is important to note that restricting the dataset to samples in which no liquid was present did not alter the main characteristics of the PDFs presented in Figs. 1 and 2.

\section{b. Characterization of $D_{m}, \sigma_{m}$, and $\mu$ distributions observed during GCPEx}

The statistical relationships found for ice-phase particles between $\sigma_{m}$ and $D_{m}$ and between $\mu$ and $D_{m}$ have a similar shape as for rainfall observations (Williams et al. 2014) but with different absolute values (Fig. 3). In particular, for small $D_{m}, \mu$ has a large spread of values ranging from -3 to greater than 10 (Fig. 3b).
To have a consistent comparison between the results presented here and those for rainfall presented by Williams et al. (2014), the frequency of occurrence plots are redone for the PSD parameters determined using the melted equivalent diameter

$$
D_{\text {melted }}=[6 m /(\pi \rho)]^{1 / 3},
$$

where $\rho$ is the density of water. Figures $3 \mathrm{c}$ and $3 \mathrm{~d}$ show the effect of replacing $D$ by $D_{\text {melted }}$ in the calculations of $D_{m}, \sigma_{m}$, and $\mu$ (herein, $D_{m}^{\text {melted }}, \sigma_{m}^{\text {melted }}$, and $\mu^{\text {melted }}$ ). Similar to what was described for these parameters computed with the maximum dimension, the statistical relationships found for ice-phase particles between $\sigma_{m}^{\text {melted }}$ and $D_{m}^{\text {melted }}$ and between $\mu^{\text {melted }}$ and $D_{m}^{\text {melted }}$ have a similar shape as for rainfall observations (Williams et al. 2014) 

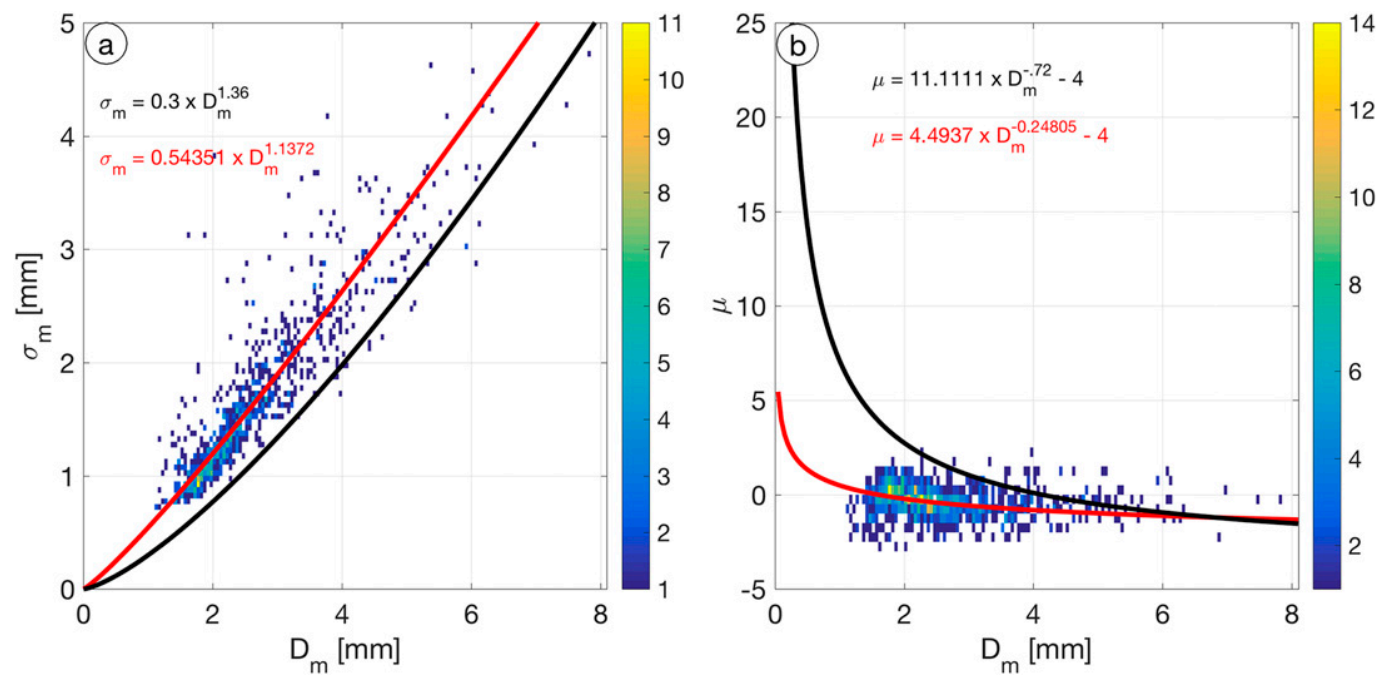

FIG. 4. As in Fig. 3, but for GPM-detectable particles $\left(Z_{e} \geq 12 \mathrm{dBZ}\right)$.

but with different absolute values (Figs. 3c,d). There is a high concentration of samples (more than $40 \%$ ) for $D_{m}^{\text {melted }}$ between 0.2 and $0.4 \mathrm{~mm}$ with $\mu^{\text {melted }}$ close to 3 . This is represented by a median $\mu^{\text {melted }}$ of 3.3. However, it is important to note that there is a clear variability of $\mu^{\text {melted }}$ with $D_{m}^{\text {melted }}$. In particular, $\mu^{\text {melted }}$ ranges from negative values to larger than 25 for $D_{m}<0.2 \mathrm{~mm}$, and it is likely to tend to 0 for $D_{m}>0.4$ (Fig. $3 \mathrm{~d}$ ). This variability is also represented by the mean and standard deviation of $\mu^{\text {melted }}$ being 5.3 and 13.3 respectively. Thus, it is important to consider this variability in the representation of $\mu$, computed with either the maximum dimension or the melted equivalent diameter.

Figures 3 and 4 show that the previously found relationship between $\mu$ and $D_{m}$ for rainfall cases
(Williams et al. 2014) is not representative of ice-phase particles and that there is a clear necessity to use different relationships for retrieving particles distributions of different precipitation types. Assuming a constant $\mu$ represents a large uncertainty for any retrieval algorithm for ice-phase particles. However, when considering particles within the detectability range of the GPM DPR of $Z_{e}>12 \mathrm{~dB} Z$, this broad range of $\mu$ values decreases (Fig. $4 \mathrm{~b}$ ). The ice-phase PSDs observed during GCPEx that are within the detectability range of the GPM DPR (above the red line in Fig. 5) were not likely to have $\mu>1$. In particular, only $3 \%$ of the ice-phase PSDs observed during GCPEx within the detectability range of the GPM DPR have $\mu \geq 3$. Thus, the current GPM algorithm assumption of $\mu=3$
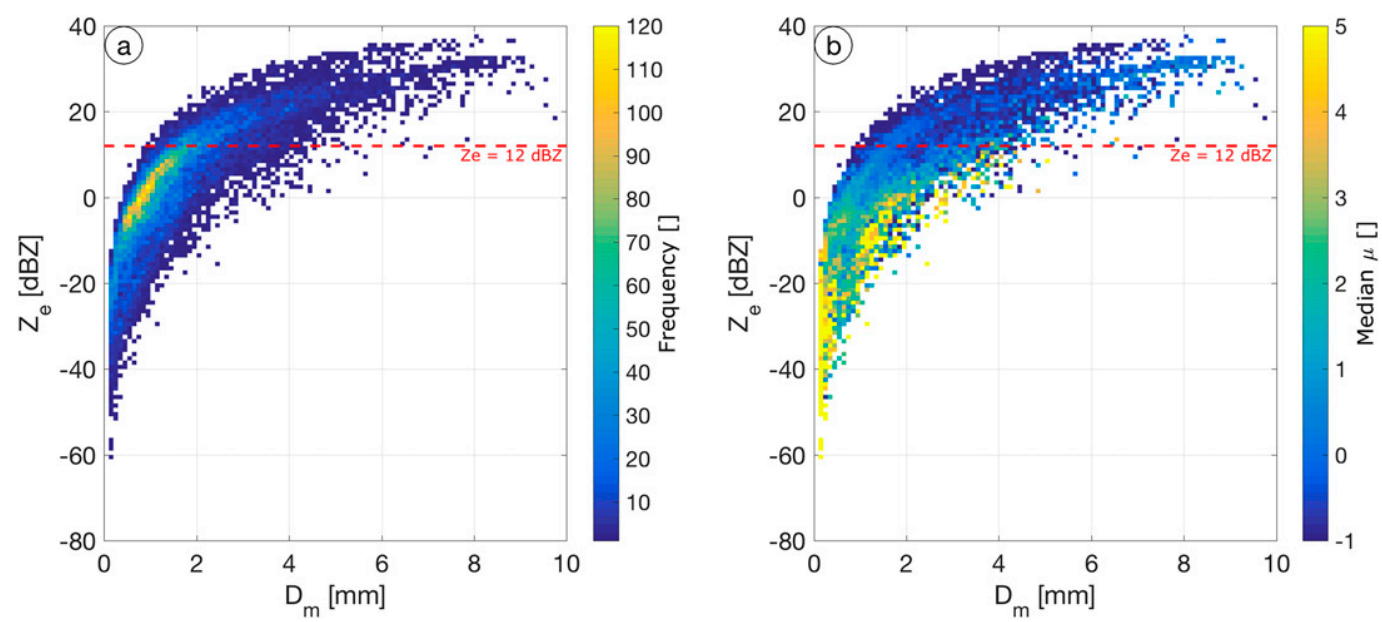

FIG. 5. (a) Joint frequency of occurrence of $Z_{e}$ as a function of $D_{m}$, and (b) median $\mu$ as a function of $Z_{e}$ and $D_{m}$. The minimum detectable signal for the DPR on board the GPM $(12 \mathrm{~dB} Z)$ is shown with a dashed red line. 

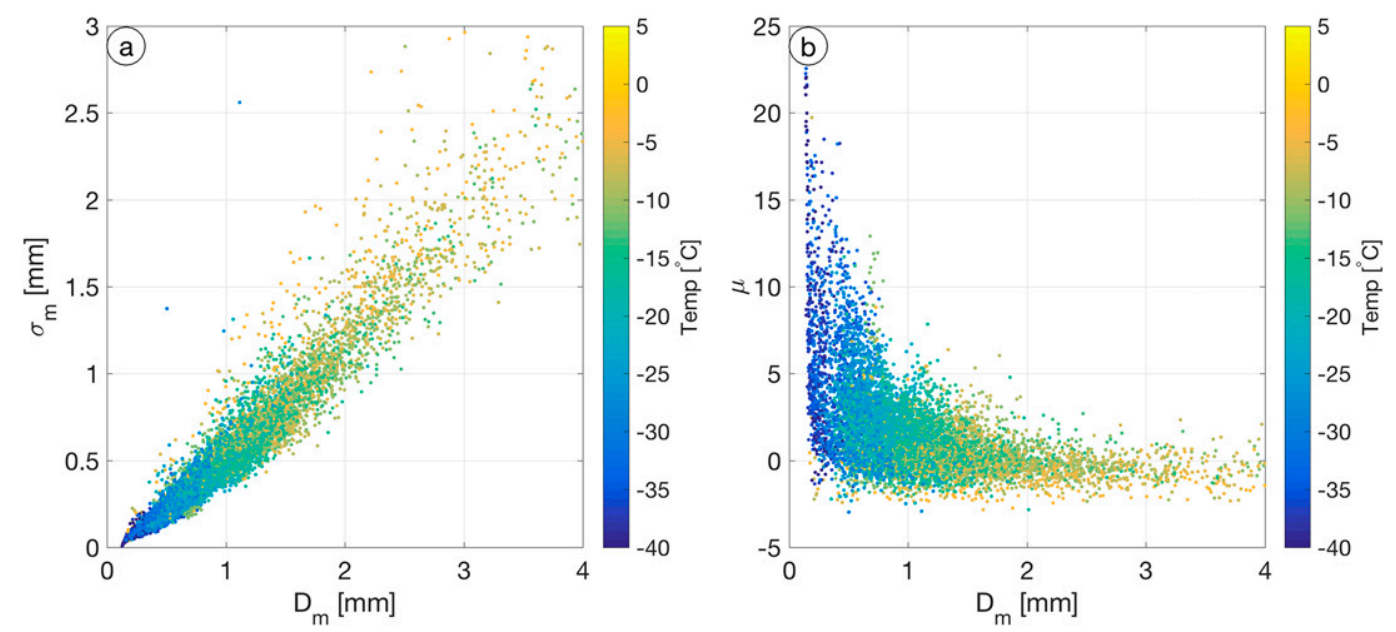

FIG. 6. Scatterplot of (a) $\sigma_{m}$ and (b) $\mu$ as a function of $D_{m}$, with the colors representing the temperature at which the observations were made.

overestimates the vast majority of $\mu$ values observed during GCPEx. Given that a large value of $\mu$ indicates a large tail in the PSD, the current GPM algorithm assumes the presence of larger particles in the retrieved PSD than are present (Fig. 4b).

The data collected during GCPEx show that the best statistical relationship, as determined by a polynomial curve fitting that is the best fit (in a least squares sense) between $\mu$ and $D_{m}$ for ice-phase particles is given by

$$
\mu\left(D_{m}\right)=5.10 \mathrm{~mm}^{0.41} D_{m}^{-0.41}-4
$$

The best statistical relationship between $\mu$ and $D_{m}$ for ice-phase particles in the detectability range of the GPM DPR algorithm is given by

$$
\mu\left(D_{m}\right)=4.49 \mathrm{~mm}^{0.25} D_{m}^{-0.25}-4 .
$$

The mean-mass diameter shows a positive relationship with temperature for both the $\mu-D_{m}$ and $\sigma_{m}-D_{m}$ distributions, implying that the temperature dependency of the shape and width of the distribution is likely to be implicitly included when considering the PSD dependency on $D_{m}$ (Fig. 6).

\section{c. Comparison of different PSD estimations}

The validity of the framework described in the previous section for the representation of PSDs is tested with independent measurements of IWC and $Z_{e}$. Reflectivity can be estimated from the PSD as

$$
Z_{e}=\frac{10^{18} \lambda^{4}}{0.93 \pi^{5}} \sum_{D_{\min }}^{D_{\max }} n(D) \sigma_{b} \Delta D,
$$

where $\lambda$ is the wavelength; in this case, $\lambda=5.33 \mathrm{~cm}$ to compare the estimations with the King City C-Band radar, and $\left\langle\sigma_{b}\right\rangle$ is the ensemble-average backscatter cross section.

Following the self-similar Rayleigh-Gans approximation (Hogan and Westbrook 2014),

$$
\begin{aligned}
\sigma_{b}= & \frac{9 \pi k^{4}|K|^{2} V^{2}}{16}\left\{\cos ^{2}(x)\left[\left(1+\frac{\kappa}{3}\right)\left(\frac{1}{2 x+\pi}-\frac{1}{2 x-\pi}\right)-\kappa\left(\frac{1}{2 x+3 \pi}-\frac{1}{2 x-3 \pi}\right)\right]^{2}\right. \\
& \left.+\beta \sum_{j=1}^{n}(2 j)^{-\gamma} \sin ^{2}(x)\left[\frac{1}{(2 x+2 \pi j)^{2}}+\frac{1}{(2 x-2 \pi j)^{2}}\right]\right\}
\end{aligned}
$$

where $k$ is the wavenumber, $x=k D$, and $K=(\varepsilon-1) /$ $(\varepsilon+2)$ with $\varepsilon$ being the dielectric constant of solid ice; $\kappa, \beta$, and $\gamma$ are the coefficients $0.19,0.23$, and $5 / 3$ respectably, and $V$ is the volume of the precipitating particle calculated assuming the particle shape can be represented by an ellipsoid of axis ration of 0.6 (Hogan et al. 2012) so that

$$
V=\frac{a D^{b}}{\rho_{i}}=\frac{a(0.6 D)^{b}}{\rho_{i}} .
$$


Ice water content can be calculated as

$$
\begin{aligned}
\mathrm{IWC} & =\int_{0}^{\infty} \operatorname{mass} \times N(D) d D=\int_{0}^{\infty} a D^{b} N_{0} D^{\mu} e^{-\lambda D} d D \\
& =a N_{0} \frac{\Gamma^{b+\mu+1}}{\lambda^{b+\mu+1}} .
\end{aligned}
$$

IWC comparisons are made between the observed values of TWC from the Nevzorov probe mounted on the UND Citation and estimates [following Eq. (15)] from in situ PSDs as sampled by the Citation, and from reconstructed PSDs using the moment-based method (following the method described in section 3), the Field et al. (2007) parameterization, and the lowest most likely estimate (i.e., lowest $\chi^{2}$ goodness of fit) using the incomplete gamma-fitting technique (IGF; McFarquhar et al. 2015). The IGF technique estimates a volume of equally realizable solutions in $\left(N_{0}\right.$, $\lambda, \mu)$ phase space that characterized every single PSD or a family of PSDs obtained in similar conditions. This is done by minimizing the $\chi^{2}$ difference between observed moments of the PSD (the first, third, and sixth moments of the PSD are used here) and those estimated from the fit parameters (McFarquhar et al. 2015). From the generated volume the pair of $N_{0}, \lambda$ that give the minimum $\chi^{2}$ for a specific fixed value of $\mu$ can be determined.

The estimated TWC from the IGF method is restricted to the minimum and maximum dimension of the sampled particles $\left(D_{\min }=75 \mu \mathrm{m}\right.$ and $\left.D_{\max }=27.5 \mathrm{~mm}\right)$. On the other hand, PSD-based estimates are computed following the complete gamma function definition, and thus are integrating over all sizes from zero to infinity [Eq. (15)]. When comparing the difference between the incomplete (between $D_{\min }$ and $D_{\max }$ ) and the complete gamma functions for the observed GCPEx PSDs, it can be shown that the contribution of the particles with a diameter smaller than $D_{\min }$ and larger than $D_{\max }$ to IWC is smaller than $0.2 \%$. Therefore, the comparison shown here between the observed TWC and the different estimates from reconstructed PSDs following Eq. (15) is appropriate.

The retrieval of IWC from the sampled PSD and the different PSD reconstructions lead to similar estimates, with a mean underestimation of IWC $<10 \%$ with respect to the value sampled by the Nevzorov probe (Fig. 7 and Table 1). Considering observations within the detectability range of the GPM satellite $\left(Z_{e} \geq 12 \mathrm{~dB} Z\right)$ the inaccuracy increases to $30 \%$ positive bias for IWC estimations from reconstructed PSDs (Table 1). Overall, the estimated IWCs following the IGF and momentbased methods are slightly closer to the observed value, by $2 \%$ and $4 \%$ for all ice-phase particle and GPM-detectable PSDs, respectively, than applying the
Field et al. (2007) parameterization (Table 1). In particular, for $D_{m}>3 \mathrm{~mm}$, all IWC estimations analyzed in this work are likely to overestimate the observed IWC when compared with the Nevzorov probe (Figs. 7 and 8). One possible reason for this is that the Nevzorov probe could be underestimating IWC during conditions containing PSDs with large particles (and thus large $D_{m}$ ) because of particle shattering and bounce out (Korolev et al. 2013). Another possible reason is the dependence of the $m-D$ relationship on particle habit, which implies that an incorrect selection of the $a$ and $b$ parameters could lead to an incorrect estimation of the particles' mass and thus to an incorrect estimation of IWC that could be particularly important for large particles where large aggregates could be misrepresented.

Reflectivity estimated from the different PSDs [following Eq. (12)] are compared with those from the groundbased King City radar extracted along the path of the Citation following the matching criteria described in section 2c. For all sampled ice-phase particles, Fig. 9 and Table 2 show that the estimates of $Z_{e}$ based on the observed PSD, moment-based, and IGF methods have a mean and median positive bias around $8 \%$ with respect to the remotely sensed value. On the other hand, estimates using the Field et al. (2007) parameterization lead to a $37 \%$ mean and a $17 \%$ median overestimation of the remotely sensed reflectivity. All $Z_{e}$ estimates have a large spread for smaller values of $D_{m}$ (Fig. 9) with some outliers representing differences larger than $10 \mathrm{~dB} Z$. For $D_{m}>1 \mathrm{~mm}$ the estimation from the moment-based and IGF methodologies tend to the observed $Z_{e}$ (Fig. 9). Thus, considering only the observations within the detectability range of the GPM satellite, the median overestimation decreases to a $2 \%$ positive bias for estimations from the observed PSD and the reconstructed PSD following the moment-based and IGF methods (Fig. 10 and Table 2). However, applying the Field et al. (2007) parameterization leads to a mean (median) underestimation of the observed $Z_{e}$ of $78 \%(45 \%)$ for the observations with $Z_{e} \geq 12 \mathrm{dBZ}$ (Fig. 10b and Table 2).

Discrepancies when comparing reflectivity from a ground-based radar with estimates from in situ PSDs are expected. Similar to the errors found in the IWC estimates, the uncertainty in the mass-dimension relationship can contribute (this factor is analyzed in more detail in section 4); in the case of $Z_{e}$, the different sample volumes and the poor sensitivity of a C-band radar to small particles can also have an impact.

\section{Analysis of the mass-dimension relationship}

Previous studies have parameterized the mass $m$ of ice particles as a function of their maximum dimension $D$ by 

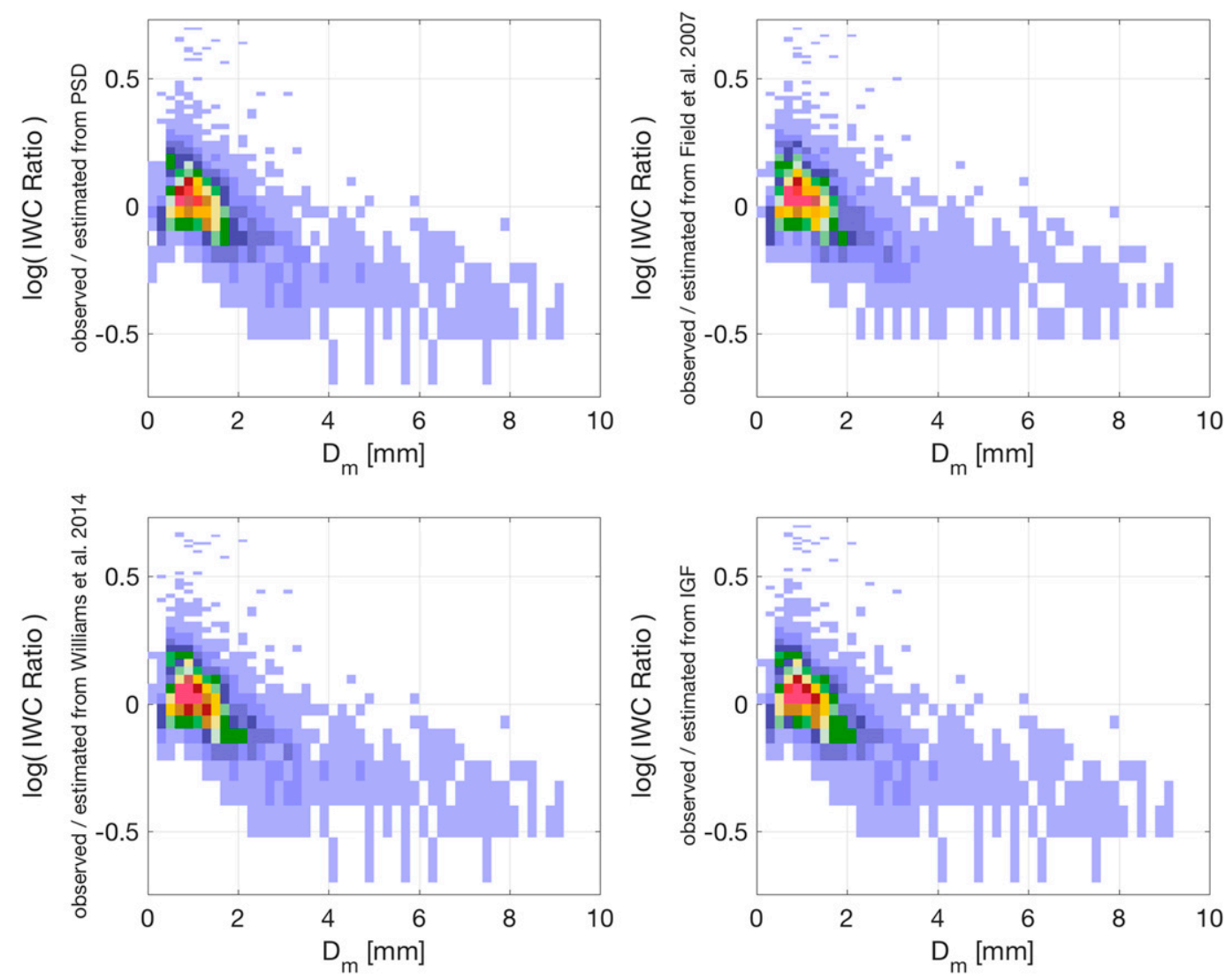

FIG. 7. Normalized joint frequency of occurrence of the ratio of IWC between observations from the Nevzorov probe on board the UND Citation and that estimated from different techniques, as a function of $D_{m}$, showing the difference with respect to estimations from (a) the observed PSD, (b) the Field et al. (2007) method, (c) the Williams et al. (2014) method, and (d) IGF estimates.

$m(D)=a D^{b}$, with $a$ and $b$ being empirically derived (e.g., Mitchell et al. 1990; Mitchell 1996; McFarquhar et al. 2007; Heymsfield et al. 2008, 2010; Finlon et al. 2019). There is considerable variation in published $a$ and $b$ values with the Brown and Francis (1995) relation, or its modified version for maximum dimension (Hogan et al. 2012), frequently used in algorithm development (e.g., Hogan et al. 2006; Heymsfield et al. 2008; Chase et al. 2018). However, fixed $a$ and $b$ values only characterize the average representation of a particle's mass but fail to capture the dependence of these parameters on habit, temperature, and cloud type (Heymsfield et al. 2010). Thus, Heymsfield et al. (2010) defined four different $m-D$ relationships with a constant $b$ of 2.1 but $a$ depending on the environment. Specifically, one subset of the dataset they analyzed corresponds to observations from field campaigns in a similar region to where GCPEx took place and therefore, the $m-D$ relationship found for that dataset $[m(D)=$ $\left.3.59 \times 10^{-3} \mathrm{~cm}^{-2.1} D^{2.1}\right]$ is used in this work and as the reference values to the estimations computed in this section.

TABLE 1. Mean and median values of the ratio between TWC from the Nevzorov probe on board the UND Citation and the IWC estimated from the observed PSD (IWC $\left(\mathrm{IWC}_{\text {moment }}\right)$, and the IGF estimates $\left(\mathrm{IWC}_{\mathrm{IGF}}\right)$.

\begin{tabular}{lllll}
\hline \hline & \multicolumn{2}{c}{ All ice-phase data } & \multicolumn{2}{c}{ GPM-detectable data } \\
\cline { 2 - 3 } & \multicolumn{1}{c}{ Mean } & Median & Mean & $0.70(30 \%)$ \\
TWC/IWC & $1.08(8 \%)$ & $1.03(3 \%)$ & $0.74(26 \%)$ & $0.69(31 \%)$ \\
TWC/IWC $_{\text {Field }}$ & $1.10(10 \%)$ & $1.05(5 \%)$ & & $0.73(27 \%)$ \\
TWC/IWC $_{\text {moment }}$ & $1.08(8 \%)$ & $1.03(3 \%)$ & $0.69(31 \%)$ & $0.69(31 \%)$ \\
TWC/IWC $_{\text {IGF }}$ & $1.08(8 \%)$ & $1.03(3 \%)$ & $0.70(30 \%)$ & $0.69(31 \%)$ \\
\hline
\end{tabular}



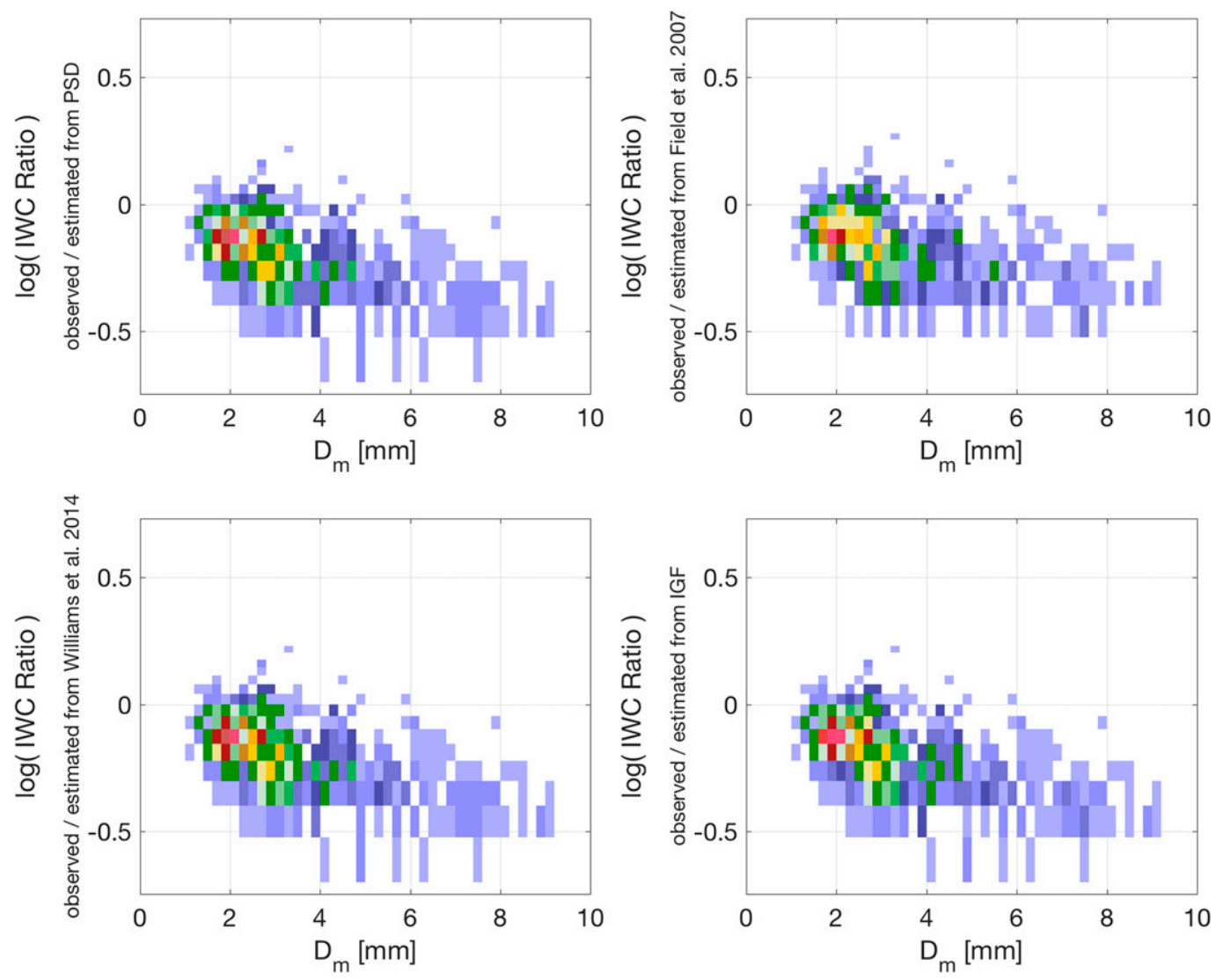

FIG. 8. As in Fig. 7, but for particles in the GPM detectability range (i.e., $Z_{e} \geq 12 \mathrm{dBZ}$ ).

Any errors in the $m-D$ relationship propagate through the $\sigma_{m}$ and $D_{m}$ calculations and affect IWC and $Z_{e}$ estimates. Thus, it is valuable to look at the level of uncertainty that fixed $a$ and $b$ coefficients introduced by the $m-D$ relationship add to the analysis. Here, the uncertainty is given by the range of possible $\sigma_{m}, D_{m}$, $\mu$, IWC, and $Z_{e}$ values estimated using the GCPEx PSDs while adjusting for possible $a$ and $b$ values following the observations shown in Heymsfield et al. (2010) for midlatitude stratiform-type clouds in the region similar to the observations analyzed here $\left(a\right.$ ranges from $3 \times 10^{-3} \mathrm{~g} \mathrm{~cm}^{-2.1}$ to $3 \times 10^{-2} \mathrm{~g} \mathrm{~cm}^{-2.1}$, and $b$ ranges from 1.5 to 3.5$)$. The $a$ and $b$ proposed in Brown and Francis (1995) of $a=$ $2.94 \times 10^{-3} \mathrm{~g} \mathrm{~cm}^{-2.1}$ and $b=1.9$ are also analyzed. From Eqs. (5), (6), and (9), it is seen that $D_{m}, \sigma_{m}$, and $\mu$ do not depend on $a$ but that changes in the exponent $b$ affect the resulting $D_{m}, \sigma_{m}$, and $\mu$. Therefore, assuming that the finding from Heymsfield et al. (2010) of $b$ in the $m-D$ relationship is correct, there would be no additional error propagated through the $D_{m}, \sigma_{m}$, and $\mu$ calculations as a result of using different $a$ assumptions (Figs. 11a-c). On the other hand, an unfitting selection of coefficient $b$ leads to minor biases in $\mu, D_{m}$ and $\sigma_{m}$. Considering the variety of $b$ coefficient present in the literature, applying a small value of $b(b=1.5)$ is likely to cause an underestimation of $12 \%$ for $D_{m}$ and $9 \%$ for $\sigma_{m}$ and an overestimation of $20 \%$ for $\mu$ (Figs. 11a-c). Likewise, applying a large value of $b(b=3)$ is likely to be associated with an overestimation of $19 \%$ for $D_{m}$ and $20 \%$ for $\sigma_{m}$ and an underestimation of $4 \%$ for $\mu$ (Figs. 11a-c).

The impact of $a$ and $b$ becomes significant when calculating different moments of the distribution, such as IWC and $Z_{e}$, for which applying a large value of $b(b=3)$ is associated with a more than $50 \%$ overestimation of $Z_{e}$ and an underestimation of $3 \%$ for IWC (Figs. 11d,e) and applying a small $b$ leads to an underestimation of $44 \%$ for $Z_{e}$ and an overestimation of almost 4 times the reference value of IWC (Figs. 11d,e). As previously mentioned, applying different $a$ values in the $m-D$ relationship has no impact on $D_{m}, \sigma_{m}$, and $\mu$ but does affect the estimates of $Z_{e}$ and IWC. Applying a small value of $a\left(a=3 \times 10^{-4} \mathrm{~g} \mathrm{~cm}^{-2.1}\right)$ is likely to cause a slight underestimation of $9 \%$ for IWC but considerably decreases $Z_{e}$, going from the estimated referenced value of $14 \mathrm{dBZ}$ to a value of $-7.6 \mathrm{~dB} Z$ (Figs. 11d,e). On the other hand, applying a large value of $a(a=3 \times$ $10^{-2} \mathrm{~g} \mathrm{~cm}^{-2.1}$ ) leads to an overestimation of more than 8 times the referenced value of IWC and 2 times the 

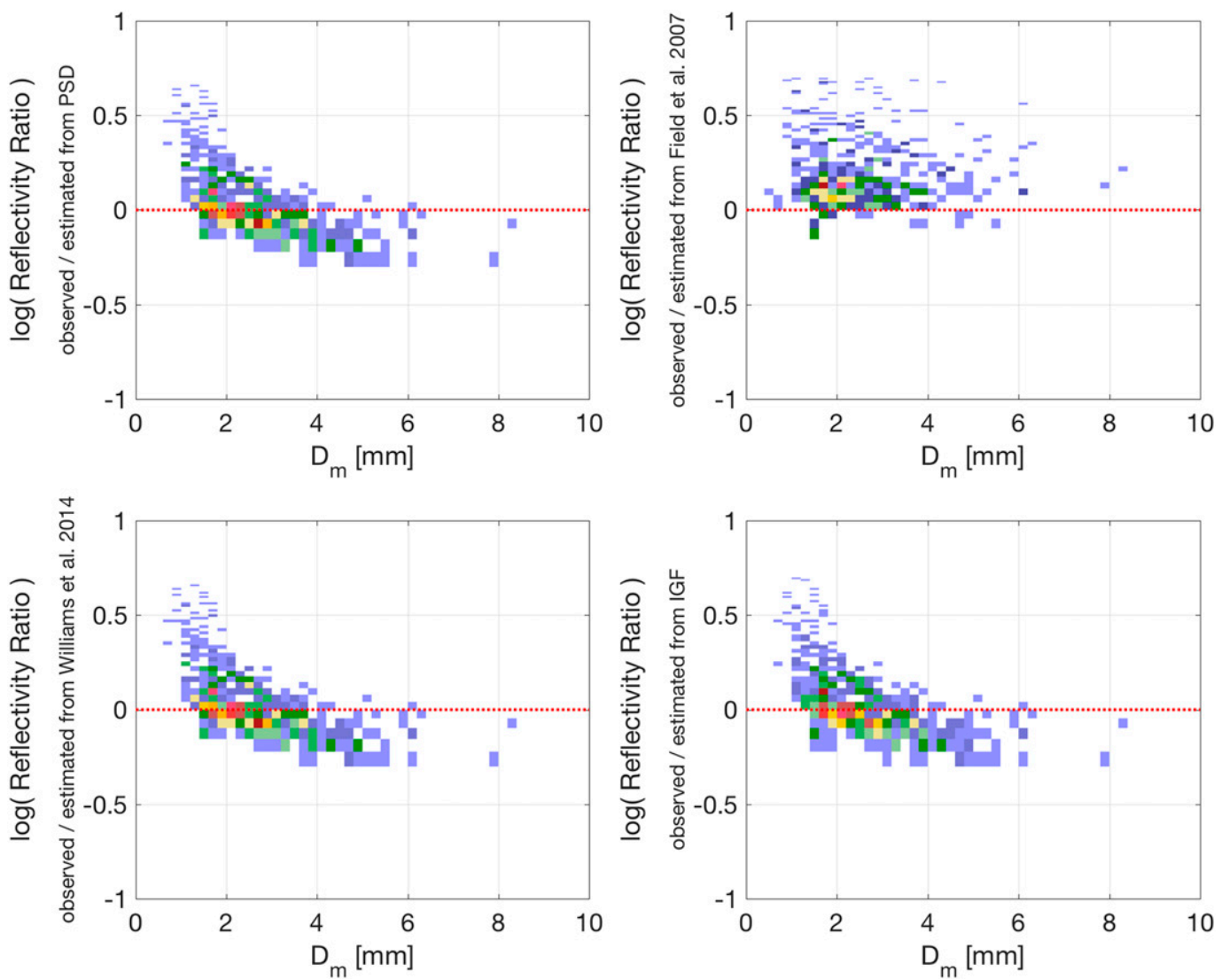

FIG. 9. As in Fig. 7, but for $Z_{e}$. The observed $Z_{e}$ corresponds to the matched effective reflectivity from the King City C-band radar along the path of the UND Citation.

referenced $Z_{e}$ values (Figs. 11d,e). In particular, when comparing the results of using the $a$ and $b$ coefficients from Heymsfield et al. (2010) versus the ones introduced by Brown and Francis (1995) there is less than a 5\% discrepancy in $D_{m}, \sigma_{m}$, and $\mu$, but as it propagates into the calculations for the different variables the error amplifies to $40 \%$ overestimation in IWC and $25 \%$ underestimation in $Z_{e}$. It is important to note, however, that the covariability of $a$ and $b$ was not considered here (e.g., Finlon et al. 2019).

The large spread in the estimations of $Z_{e}$ and IWC shows the severe impact that the selection of $a$ and $b$ in the mass-dimension relationship, even from realistic values previously used in the literature, has in the calculations of these variables. This could represent a reason for the differences found when comparing estimates of $Z_{e}$ and IWC from the sampled and reconstructed PSDs with the independently observed values (Figs. 7-10).

\section{PSD parameterization for ice-phase particles}

Herein a parameterization of the PSD that improves the consistency of the retrievals for ice-phase precipitation is presented using GCPEx PSD observations. This is of fundamental use for the atmospheric modeling

TABLE 2. As in Table 1,but for effective reflectivity. The observed $Z_{e}$ corresponds to the matched effective reflectivity from the King City C-band radar along the path of the UND Citation.

\begin{tabular}{|c|c|c|c|c|}
\hline & \multicolumn{2}{|c|}{ All ice-phase data } & \multicolumn{2}{|c|}{ GPM-detectable data } \\
\hline & Mean & Median & Mean & Median \\
\hline$Z_{e}($ radar $) / Z_{e}(\mathrm{PSD})$ & $1.08(8 \%)$ & $0.93(7 \%)$ & $1.22(22 \%)$ & $1.02(2 \%)$ \\
\hline$Z_{e}($ radar $) / Z_{e}($ Field $)$ & $1.37(37 \%)$ & $1.17(17 \%)$ & $1.78(78 \%)$ & $1.45(45 \%)$ \\
\hline$Z_{e}($ radar $) / Z_{e}$ (moment) & $1.08(8 \%)$ & $0.93(7 \%)$ & $1.23(23 \%)$ & $1.02(2 \%)$ \\
\hline$Z_{e}($ radar $) / Z_{e}(\mathrm{IGF})$ & $1.07(7 \%)$ & $0.92(8 \%)$ & $1.23(23 \%)$ & $1.01(1 \%)$ \\
\hline
\end{tabular}



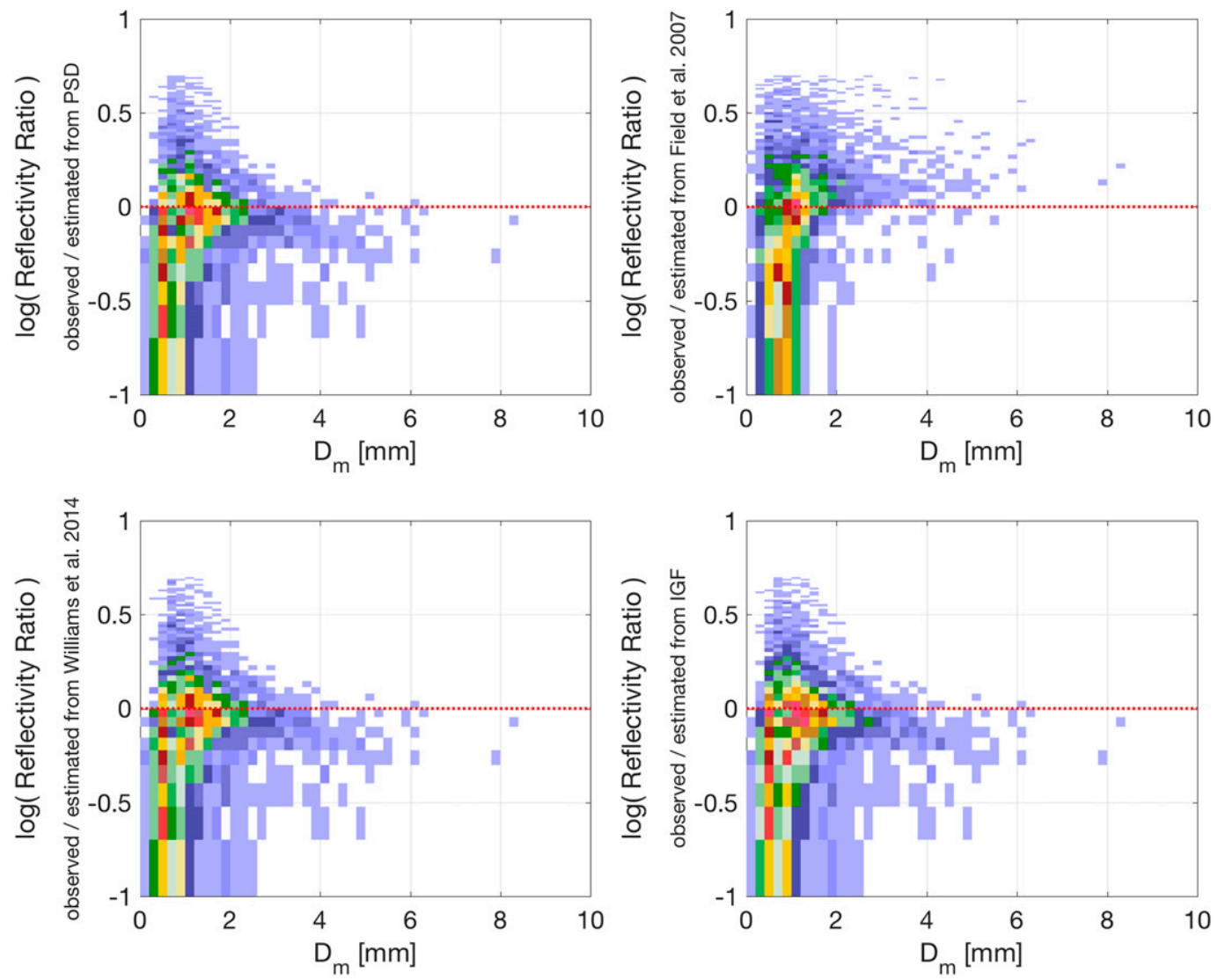

FIG. 10. As in Fig. 9, but for particles in the GPM detectability range (i.e., $Z_{e} \geq 12 \mathrm{~dB} Z$ ).

community and should help to guide the assumptions for retrievals development in double-moment microphysical schemes. Expanding Eq. (3) leads to

$$
\begin{aligned}
D_{m} & =\frac{\int_{0}^{\infty} m N(D) D d D}{\int_{0}^{\infty} m N(D) d D}=\frac{\int_{0}^{\infty} a N_{0} D^{b+\mu+1} e^{-\lambda D} d D}{\int_{0}^{\infty} a N_{0} D^{b+\mu} e^{-\lambda D} d D} \\
& =\frac{\Gamma(b+1+\mu+1)}{\lambda^{b+1+\mu+1}} \frac{\lambda^{b+\mu+1}}{\Gamma(b+\mu+1)}=\frac{b+\mu+1}{\lambda},
\end{aligned}
$$

which can be rearranged to obtain

$$
\lambda=(b+\mu+1) / D_{m} .
$$

From Eq. (15) it follows that

$$
N_{0}=\operatorname{IWC} \frac{\lambda^{b+\mu+1}}{a \Gamma^{b+\mu+1}}
$$

Therefore, from the best fit between $\mu$ and $D_{m}$ for ice-phase particles found in this work [Eq. (11)] and Eqs. (17) and (18), the PSD for ice-phase particles
$\left[N(D)=N_{0} D^{\mu} e^{-\lambda D}\right]$ can be described with only two input variables, $D_{m}$ and IWC. Note that in the derivation of the best fit between $\mu$ and $D_{m}$ the exponent in the mass-dimension relationship was assumed to be 2.1. However, any value of $a$ and $b$ in a mass-dimension relation could be used within the relations above.

\section{Estimated $Z_{e}$ using different $\mu$ constraints}

The difference between $Z_{e}$ estimated from the momentbased method with varying $\mu$ and those estimated for different constant values of $\mu$ and for $\mu$ as a function of $D_{m}$ [Eqs. (10a) and (10b)] is shown in Figs. 12 and 13. Figure 12 shows the impact of varying $\mu$ for the entire ice-phase dataset collected during GCPEx. As expected from Fig. 3, using a constant $\mu$ or $\mu$ as a function of $D_{m}$ for the entire dataset gives a large spread in the estimated $Z_{e}$, especially for $D_{m}<2 \mathrm{~mm}$. For example, for $D_{m}=1 \mathrm{~mm}$ all estimates of $Z_{e}$ can present more than a $50 \%$ error (Fig. 12). The moment-based method with $\mu=0$ slightly overestimates $Z_{e}$ with a $3 \%$ mean bias (Fig. 12a). This overestimation increases as the selected $\mu$ value increases. For example, using $\mu=3$, as currently 

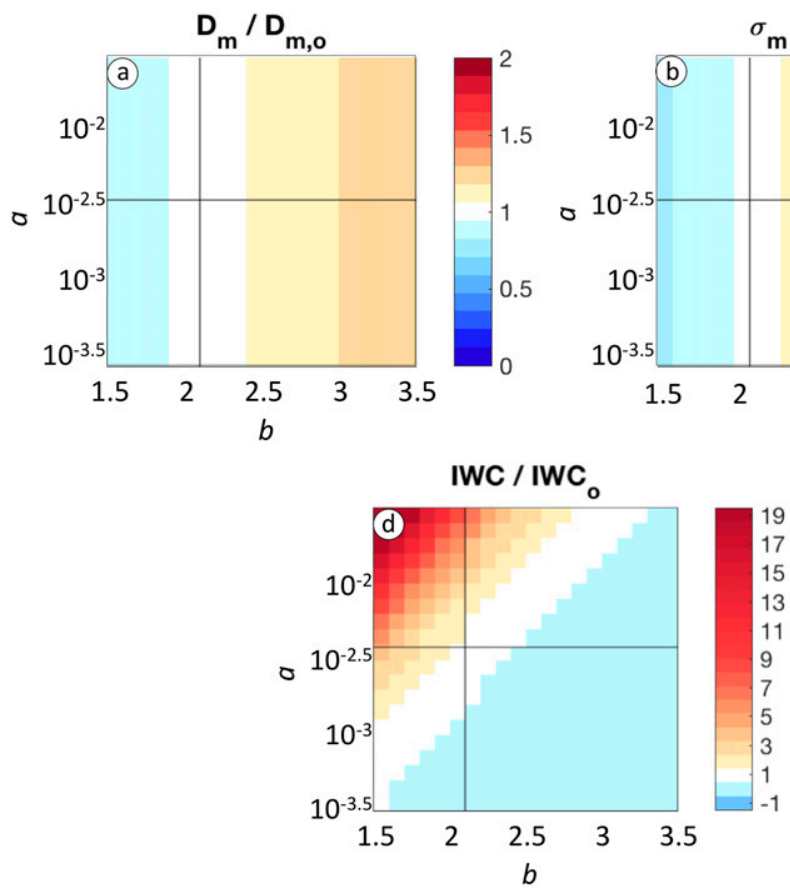
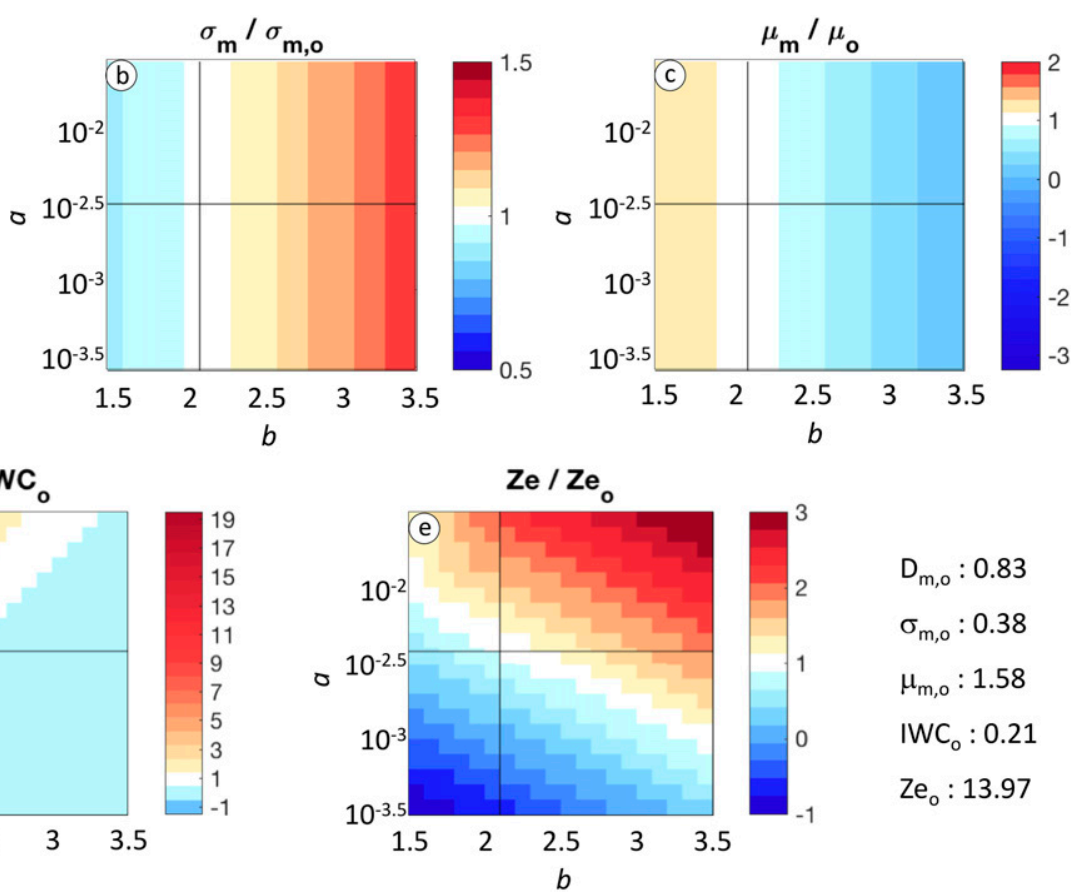

$\mathrm{D}_{\mathrm{m}, \mathrm{o}}: 0.83$

$\sigma_{m, 0}: 0.38$

$\mu_{\mathrm{m}, \mathrm{o}}: 1.58$

$I W C_{0}: 0.21$

$\mathrm{Ze}_{\mathrm{o}}: 13.97$

FIG. 11. Influence of different $a$ and $b$ parameters, via the mass-diameter relation, in (a) $D_{m}$, (b) $\sigma_{m}$, (c) $\mu$, (d) IWC, and (e) $Z_{e}$. This effect is quantified by estimating the mass for different $a$ and $b$ and calculating the associated moments and variables normalized by the ones using $a_{o}$ and $b_{o}$. Therefore, a value of 2 or 0.5 indicates that, for the corresponding $a$ and $b$ value, there is a $100 \%$ positive or $50 \%$ negative bias, respectively, in the estimated variable. The $a$ and $b$ values used in this work (Heymsfield et al. 2010) are indicated with the black lines.

used in the GPM algorithm, leads to a $1 \%$ bias in the estimated $Z_{e}$, and using $\mu=10$ represents a $3 \%$ mean overestimation (Fig. 12 and Table 3). Applying the best fit between $\mu$ and $D_{m}$ for ice-phase particles [Eq. (11a)] leads to a better representation of the small particles $\left(D_{m}<2.5 \mathrm{~mm}\right)$ and a median bias smaller than $1 \%$ (Fig. 12d and Table 3). As $D_{m}$ increases, the spread between $Z_{e}$ estimates with varying $\mu$ and the estimates under different $\mu$ assumptions decreases (Fig. 12). Therefore, restricting the dataset to observations in the detectability range of the GPM DPR leads to overall a smaller spread and a better fit given an appropriate selection of $\mu$ (Fig. 13 and Table 3). Increasing the $\mu$ value used in the calculations of $Z_{e}$ leads to lower estimates of $Z_{e}$, using a constant value of $\mu=0$ leads to a $2 \%$ mean bias, using $\mu=3$ leads to a bias of $5 \%$, and using $\mu=10$ leads to a $7 \%$ bias (Figs. 13a-c and Table 3). These findings are consistent with the median of the distribution for the different estimates (Table 3). Moreover, applying the best fit between $\mu$ and $D_{m}$ for ice-phase particles in the detectability range of the GPM DPR [Eq. (11b)] leads to the lowest discrepancies, with a mean and median bias smaller than 1\% (Fig. 13d and Table 3). It is important to note that these statistical values show that, on average, choosing an exponential distribution (i.e.: $\mu=0$ ) versus a gamma distribution seem comparable. However, the variability of the $\mu$ parameter is a function of $D_{m}$ and the benefits of using the gamma distribution is present for small mass-weighted mean diameter. For example, assuming that the PSD follows an exponential distribution for $D_{m}<1 \mathrm{~mm}$ leads to an error 3 times as large as that obtained when assuming that the PSD follows a gamma distribution with $\mu$ as a function of $D_{m}$.

\section{Summary and conclusions}

Both satellite retrieval algorithms and model microphysical parameterizations are in need of guidance from observations to improve the representation of ice-phase quantities and processes. Here, in situ observations collected during GCPEx were analyzed to expand the method originally proposed by Williams et al. (2014) for raindrop mass distributions to ice-phase particles. This technique parameterizes gamma PSD characteristics by calculating an independent $\mu-D_{m}$ constraint for the $\mu$ parameter. The statistical relationships between $\mu$ and $D_{m}$ found for ice-phase particles [either by using the maximum dimension or the equivalent melted diameter in Eqs. (3)-(10)] differ from the one found for rainfall observations (Figs. 3 and 4). In particular, using the maximum dimension of the sampled particle, for GCPEx there 

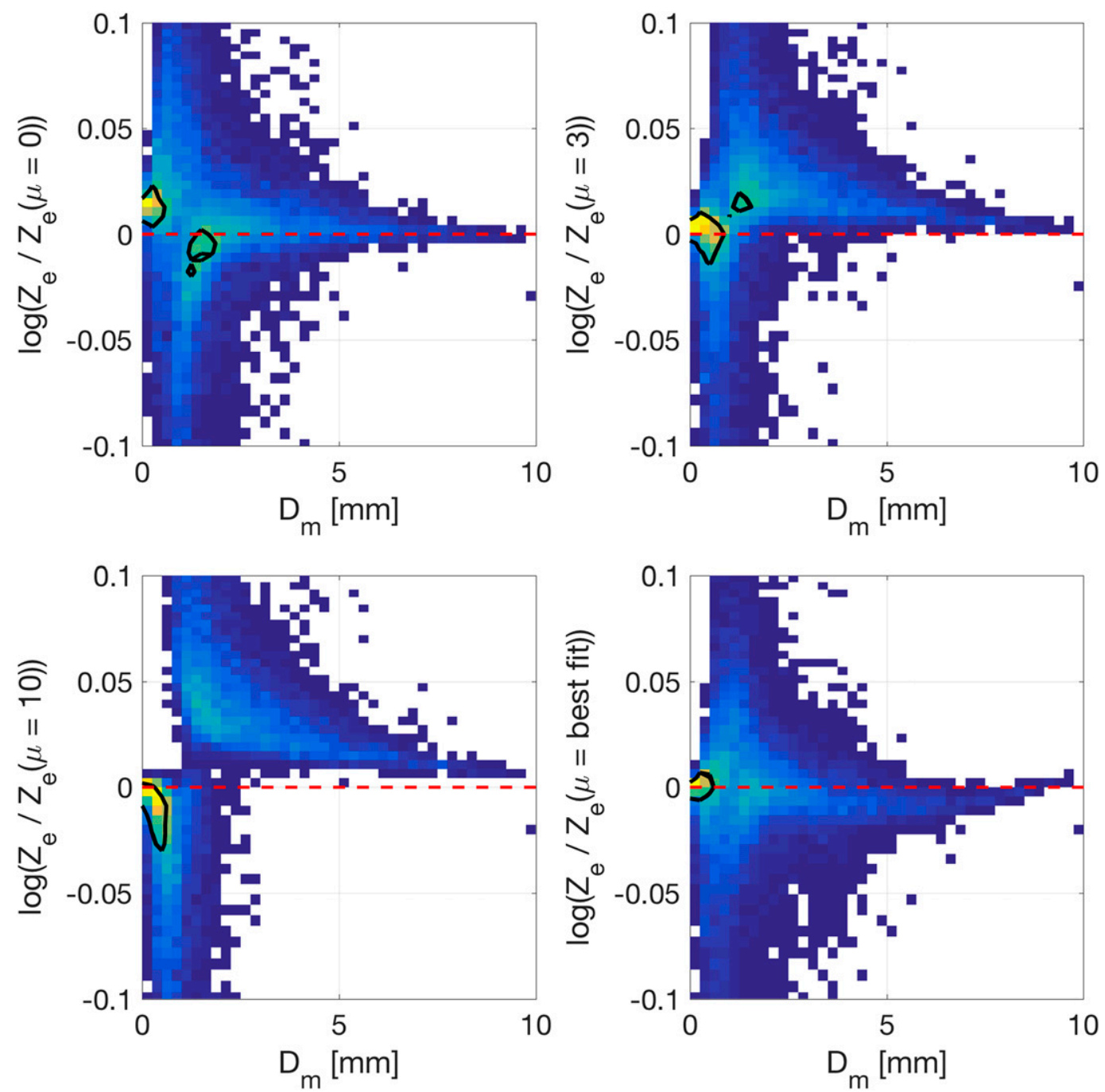

FIG. 12. Normalized joint frequency of occurrence of the ratio between the estimated $Z_{e}$ with varying $\mu$ and $Z_{e}$ estimated with (a) $\mu=0$, (b) $\mu=3$, (c) $\mu=10$, and (d) $\mu\left(D_{m}\right)=5.098 \times D_{m}^{-0.41}-4$ as a function of $D_{m}$. Frequencies larger than $50 \%$ are enclosed by the solid black line, and a zero difference between the estimated reflectivities is marked with a dotted red line.

is a large spread of $\mu$, ranging from -3 to greater than 10 for $D_{m}<1 \mathrm{~mm}$ (Fig. 3). Thus, any algorithm designed for ice-phase particles that assumes a constant $\mu$ will have a large uncertainty in any retrieved variable, especially for small $D_{m}$ for conditions similar to those sampled during GCPEx. Furthermore, given that the relationship previously found between $\mu$ and $D_{m}$ for rainfall is not representative of ice-phase particles, the necessity to use different relationships for retrievals of different precipitation types is evident. Thus, more realistic microphysical parameterizations across the full range of observable ice-phase clouds require an adaptable constraint that considers the observed variability in $\mu$. Here, the best statistical relationship between $\mu$ and $D_{m}$ for all ice-phase particles collected during GCPEx is given in Eq. (11a). When considering only observations within the detectability range of the GPM DPR of $Z_{e} \geq 12 \mathrm{~dB} Z, \mu$ does not exhibit a broad range of values and is likely to be around 0 (Fig. 4 ). This result indicates that it is critical to allow $\mu$ close to 0 for a better representation of GPM-detectable ice-phase PSDs and that a different relationship between $\mu$ and $D_{m}$ is needed [Eq. (11b)].

The effect of introducing the relationship between $\mu$ and $D_{m}$ in the estimation of effective reflectivity and ice water content for ice-phase particles was analyzed in section $3 \mathrm{c}$. When compared with independently observed values of $Z_{e}$ and IWC, the retrieved variables from the reconstructed PSD including the $\mu$ and $D_{m}$ constraint had an $8 \%$ mean expected error in both 

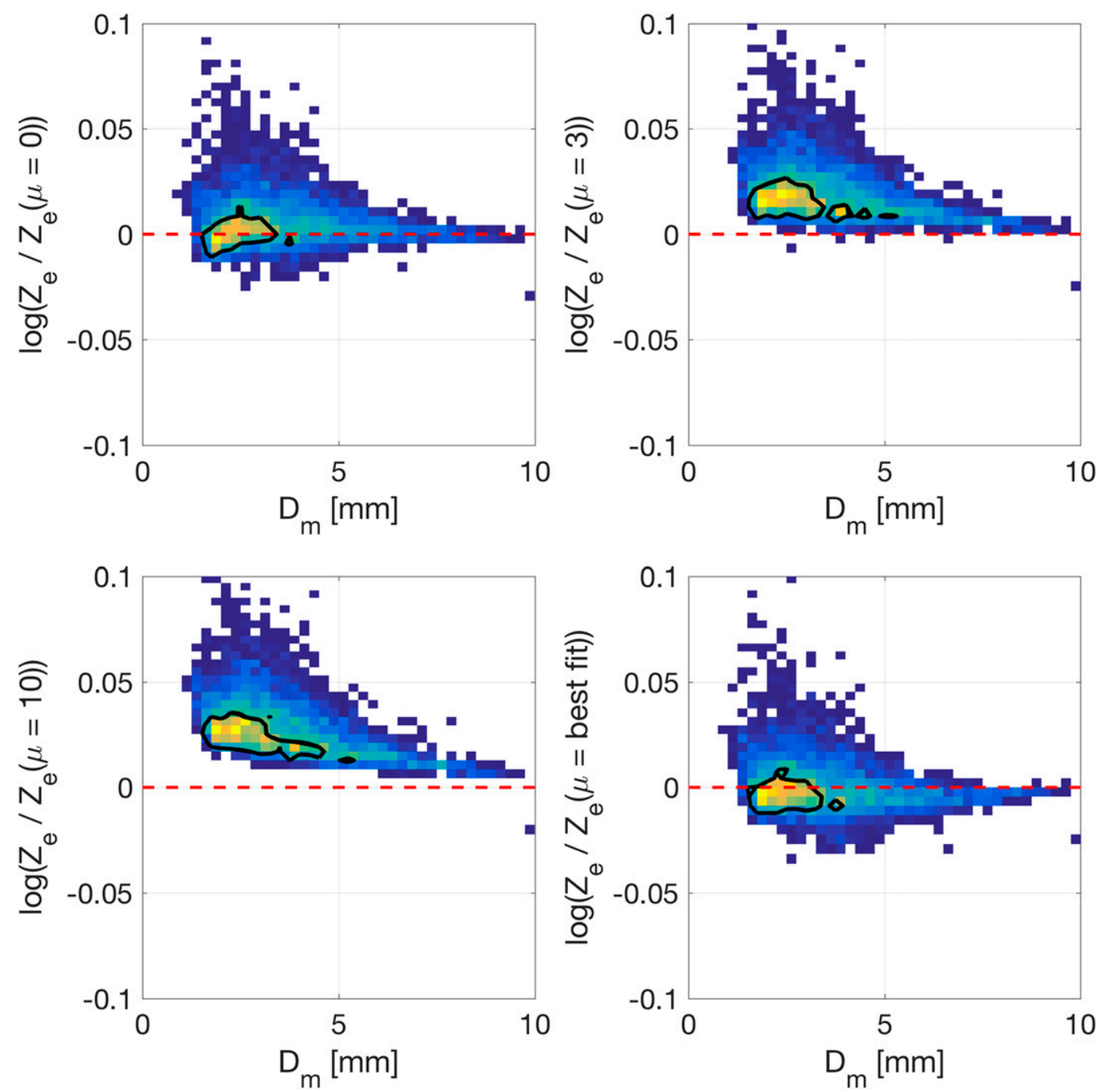

FIG. 13. As in Fig. 12, but for particles in the GPM detectability range (i.e., $Z_{e} \geq 12 \mathrm{dBZ}$ ) so that the relationship used in (d) is $\mu\left(D_{m}\right)=4.49 \times D_{m}^{-0.25}-4$ [Eq. (11b)].

variables (Tables 1 and 2). Furthermore, this error is smaller than or equivalent to the expected error when estimating these variables following other techniques or parameterizations (Tables 1 and 2). In particular, applying the Field et al. (2007) parameterization to estimate $Z_{e}$ leads to a mean $37 \%$ overall overestimation and a $78 \%$ mean overestimation for particles with $Z_{e} \geq$ $12 \mathrm{dBZ}$ (Fig. 10b and Table 2). This is in contraposition to the $8 \%$ and $22 \%$ when applying the $\mu$ and $D_{m}$ constraint to all ice-phase particle and GPM-detectable PSDs, respectably (Table 2). This shows that, especially for $Z_{e}$ estimates, parameterizing the gamma PSD

TABLE 3. Mean and median values of the ratio between estimated $Z_{e}$ with varying $\mu$ and that estimated with $\mu=0\left[Z_{e} / Z_{e}(\mu=0)\right], \mu=3$ $\left[Z_{e} / Z_{e}(\mu=3)\right], \mu=10\left[Z_{e} / Z_{e}(\mu=10)\right]$, and $\mu\left(D_{m}\right)=5.098 \times D_{m}^{-0.41}-4$ [Eq. (11a)] for all ice-phase data and $\mu\left(D_{m}\right)=4.49 \times D_{m}^{-0.25}-4$ [Eq. (11b)] for $Z_{e}>12 \mathrm{~dB} Z\left[Z_{e} / Z_{e}(\mu=\right.$ best fit $\left.)\right]$.

\begin{tabular}{ccccc}
\hline \hline & \multicolumn{2}{c}{ All ice-phase data } & \multicolumn{2}{c}{ GPM-detectable data } \\
\cline { 2 - 3 } & Mean & Median & Mean & $1.02(2 \%)$ \\
\hline$Z_{e} / Z_{e}(\mu=0)$ & $0.97(3 \%)$ & $1.01(1 \%)$ & $1.05(5 \%)$ & $1.01(1 \%)$ \\
$Z_{e} / Z_{e}(\mu=3)$ & $0.99(1 \%)$ & $1.03(3 \%)$ & $1.07(7 \%)$ & $1.04(4 \%)$ \\
$Z_{e} / Z_{e}(\mu=10)$ & $0.97(3 \%)$ & $1.04(4 \%)$ & $1.06(6 \%)$ & $1(<1 \%)$ \\
$Z_{e} / Z_{e}(\mu=$ best fit $)$ & $0.96(4 \%)$ & $1(<1 \%)$ & $1 \%)$ & $(<1 \%)$ \\
\hline
\end{tabular}


by calculating a statistically independent $\mu-D_{m}$ constraint for the $\mu$ parameter represents a clear improvement to currently used algorithms in ice-phase precipitation. It is important to add that the Field et al. (2007) parameterization requires only one moment to generate a PSD estimate, whereas the parameterization presented in this work requires two inputs, such as $Z_{e}$ and DFR. In real data, these two inputs could contain measurement error that may impact the retrieved PSD parameters; the impacts of measurement errors on PSD retrievals will be a topic for future study.

This work further illustrates the variability of $\mu$ in observed ice-phase clouds and further demonstrates the impact of a constant $\mu$ on $Z_{e}$ estimates (Figs. 12 and 13). The simple assumption used in the current GPM algorithms of $\mu=3$ leads to an erroneous retrieval of $Z_{e}$, with a mean underestimation of $Z_{e}$ of $5 \%$, whereas applying the best fit found in this work between $\mu$ and $D_{m}$ reduces this to a smaller-than- $1 \%$ overestimation (Figs. 13 and Table 3). Therefore, a straightforward improvement that can be done in the current GPM algorithm is to use values of $\mu$ that are more representative of snowfall conditions for high-latitude retrievals. However, further study is needed before applying these results on a global scale because the $\mu$ parameter relationship may be regime dependent, including in mixed-phase conditions that were excluded in this study.

The impact of the selection of the $a$ and $b$ coefficients in the mass-dimension relation $m(D)=a D^{b}$ on the retrieved IWC and $Z_{e}$ was also presented. This study compared the impact of the selected $a$ and $b$ coefficients used in this work with estimates of IWC and $Z_{e}$ using a range of $a$ and $b$ values previously used in the literature. It was found that applying a large value of $b(b=3)$ is likely to cause more than $50 \%$ overestimation of $Z_{e}$ and an underestimation of $3 \%$ of IWC and that use of a small $b(b=1.5)$ leads to an underestimation of $44 \%$ for $Z_{e}$ and an overestimation of almost a factor of 4 in IWC (Fig. 11). The impact of the $a$ coefficient in the calculation of these variables is also significant; applying a small value of $a\left(a=3 \times 10^{-4} \mathrm{~g} \mathrm{~cm}^{-2.1}\right)$ is likely to cause an underestimation of $9 \%$ for IWC and a considerable underestimation of $Z_{e}$ (from an expected referenced value of $14 \mathrm{~dB} Z$ to $-7.6 \mathrm{~dB} Z)$, and applying a large value of $a\left(a=3 \times 10^{-2} \mathrm{~g} \mathrm{~cm}^{-2.1}\right)$ leads to a major overestimation in both variables: more than a factor of 8 for IWC and a factor of 2 for $Z_{e}$ (Fig. 11). This spread in the estimations of $Z_{e}$ and IWC demonstrates the need to use $a$ and $b$ parameters that are most representative of the sampled particles so as to minimize any errors in the mass calculation and thus avoid further error propagation and amplification into the calculations of different variables, including a wider variety of precipitation conditions sampled in other regions.

Acknowledgments. The authors thank two anonymous reviewers and Dmitri Moisseev for their helpful comments and suggestions that helped to improve the paper. Funding for this research was provided by NASA Precipitation Measurement Missions Grant NNX16AD80G under Ramesh Kakar. We thank all of the participants of GCPEx for collecting the data used in this study and Andrew Heymsfield and Aaron Bansemer for providing the microphysical data. Data used in this investigation are available on the NASA GHRC GCPEx data archive.

\section{REFERENCES}

Atlas, D., and C. Ulbrich, 2006: Drop size spectra and integral remote sensing parameters in the transition from convective to stratiform rain. Geophys. Res. Lett., 33, L16803, https:/ doi.org/10.1029/2006GL026824.

Barnes, S. L., 1964: A technique for maximizing details in numerical weather map analysis. J. Appl. Meteor., 3, 396-409, https://doi.org/10.1175/1520-0450(1964)003<0396:ATFMDI> 2.0.CO;2.

Baumgardner, D., and Coauthors, 2017: Cloud ice properties: In situ measurement challenges. Ice Formation and Evolution in Clouds and Precipitation: Measurement and Modeling Challenges, Meteor. Monogr., No. 58, Amer. Meteor. Soc., https:/ doi.org/10.1175/AMSMONOGRAPHS-D-16-0011.1.

Bringi, V., and V. Chandrasekar, 2001: Polarimetric Doppler Weather Radar: Principles and Applications. Cambridge University Press, $636 \mathrm{pp}$.

Brown, E. N., 1982: Ice detector evaluation for aircraft hazard warning and undercooled water content measurements. J. Aircr., 19, 980-983, https://doi.org/10.2514/3.44800.

Brown, P., and P. Francis, 1995: Improved measurements of the ice water content in cirrus using a total-water probe. J. Atmos. Oceanic Technol., 12, 410-414, https://doi.org/10.1175/15200426(1995)012<0410:IMOTIW > 2.0.CO;2.

Cao, Q., and G. Zhang, 2009: Errors in estimating raindrop size distribution parameters employing disdrometer and simulated raindrop spectra. J. Appl. Meteor. Climatol., 48, 406-425, https://doi.org/10.1175/2008JAMC2026.1.

Casella, D., G. Panegrossi, P. Sanò, A. C. Marra, S. Dietrich, B. T. Johnson, and M. S. Kulie, 2017: Evaluation of the GPM-DPR snowfall detection capability: Comparison with CloudSat-CPR. Atmos. Res., 197, 64-75, https://doi.org/10.1016/ j.atmosres.2017.06.018.

Chandrasekar, V., and V. N. Bringi, 1987: Simulation of radar reflectivity and surface measurements of rainfall. J. Atmos. Oceanic Technol., 4, 464-478, https://doi.org/10.1175/15200426(1987)004<0464:SORRAS > 2.0.CO;2.

- W. Li, and B. Zafar, 2005: Estimation of raindrop size distribution from spaceborne radar observations. IEEE Trans. Geosci. Remote Sens., 43, 1078-1086, https://doi.org/10.1109/ TGRS.2005.846130.

Chase, R. J., and Coauthors, 2018: Evaluation of triple-frequency radar retrieval of snowfall properties using coincident airborne in situ observations during OLYMPEX. Geophys. Res. Lett., $\mathbf{4 5}$, 5752-5760, https://doi.org/10.1029/2018GL077997. 
Cober, S. G., G. A. Isaac, A. V. Korolev, and J. W. Strapp, 2001: Assessing cloud-phase conditions. J. Appl. Meteor., 40, 1967-1983, https://doi.org/10.1175/1520-0450(2001)040<1967:ACPC > 2.0.CO;2.

Cohard, J., and J. Pinty, 2000: A comprehensive two-moment warm microphysical bulk scheme. I: Description and tests. Quart. J. Roy. Meteor. Soc., 126, 1815-1842, https://doi.org/ 10.1256/smsqj.56613.

Delanoë, J. M. E., A. J. Heymsfield, A. Protat, A. Bansemer, and R. J. Hogan, 2014: Normalized particle size distribution for remote sensing application. J. Geophys. Res. Atmos., 119, 4204-4227, https://doi.org/10.1002/2013JD020700.

Delene, D. and M. R Poellot, 2012: GPM Ground Validation UND Citation Cloud Microphysics GCPEX Version 1. NASA Global Hydrology Resource Center DAAC, accessed 1 October 2016, https://doi.org/10.5067/GPMGV/ GCPEX/MULTIPLE/DATA202.

Ferrier, B. S., 1994: A double-moment multiple-phase four-class bulk ice scheme. Part I: Description. J. Atmos. Sci., 51, 249-280, https:// doi.org/10.1175/1520-0469(1994)051<0249:ADMMPF > 2.0.CO;2.

Field, P. R., A. J. Heymsfield, and A. Bansemer, 2006: Shattering and particle interarrival times measured by optical array probes in ice clouds. J. Atmos. Oceanic Technol., 23, 1357-1371, https:// doi.org/10.1175/JTECH1922.1.

,-- , and -2007 : Snow size distribution parameterization for midlatitude and tropical ice clouds. J. Atmos. Sci., 64, 43464365, https://doi.org/10.1175/2007JAS2344.1.

Finlon, J. A., G. M. McFarquhar, S. W. Nesbitt, R. M. Rauber, H. Morrison, W. Wu, and P. Zhang, 2019: A novel approach to characterize the variability in mass-dimension relationships: Results from MC3E. Atmos. Chem. Phys., 19, 3621-3643, https:// doi.org/10.5194/acp-19-3621-2019.

Grecu, M., L. Tian, W. Olson, and S. Tanelli, 2011: A robust dualfrequency radar profiling algorithm. J. Appl. Meteor. Climatol., 50, 1543-1557, https://doi.org/10.1175/2011JAMC2655.1.

Haddad, Z. S., S. L. Durden, and E. Im, 1996: Parameterizing the raindrop size distribution. J. Appl. Meteor., 35, 3-13, https:// doi.org/10.1175/1520-0450(1996)035<0003:PTRSD>2.0.CO;2.

Heymsfield, A. J., 2003: Properties of tropical and midlatitude ice cloud particle ensembles. Part I: Median mass diameters and terminal velocities. J. Atmos. Sci., 60, 2573-2591, https://doi.org/ 10.1175/1520-0469(2003)060<2573:POTAMI >2.0.CO;2.

_ , and J. L. Parrish, 1978: A computational technique for increasing the effective sampling volume of the PMS twodimensional particle size spectrometer. J. Appl. Meteor., 17, 1566-1572, https://doi.org/10.1175/1520-0450(1978)017<1566: ACTFIT $>2.0 . \mathrm{CO} ; 2$.

— P. Field, and A. Bansemer, 2008: Exponential size distributions for snow. J. Atmos. Sci., 65, 4017-4031, https://doi.org/ 10.1175/2008JAS2583.1.

— C. Schmitt, A. Bansemer, and C. H. Twohy, 2010: Improved representation of ice particle masses based on observations in natural clouds. J. Atmos. Sci., 67, 3303-3318, https://doi.org/ 10.1175/2010JAS3507.1.

Hogan, R. J., and C. D. Westbrook, 2014: Equation for the microwave backscatter cross section of aggregate snowflakes using the self-similar Rayleigh-Gans approximation. J. Atmos. Sci., 71, 3292-3301, https://doi.org/10.1175/JAS-D-13-0347.1.

_ M. P. Mittermaier, and A. J. Illingworth, 2006: The retrieval of ice water content from radar reflectivity factor and temperature and its use in evaluating a mesoscale model. J. Appl. Meteor. Climatol., 45, 301-317, https://doi.org/10.1175/JAM2340.1.

—, L. Tian, P. R. A. Brown, C. D. Westbrook, A. J. Heymsfield, and J. D. Eastment, 2012: Radar scattering from ice aggregates using the horizontally aligned oblate spheroid approximation. J. Appl. Meteor. Climatol., 51, 655-671, https://doi.org/ 10.1175/JAMC-D-11-074.1.

Hong, S., J. Dudhia, and S. Chen, 2004: A revised approach to ice microphysical processes for the bulk parameterization of clouds and precipitation. Mon. Wea. Rev., 132, 103-120, https://doi.org/10.1175/1520-0493(2004)132<0103:ARATIM> 2.0.CO;2.

Hou, A., and Coauthors, 2014: The Global Precipitation Measurement Mission. Bull. Amer. Meteor. Soc., 95, 701722, https://doi.org/10.1175/BAMS-D-13-00164.1.

Hudak, D., 2013: GPM ground validation dual polarized Cband Doppler radar King City GCPEx. NASA EOSDIS Global Hydrology Resource Center DAAC, accessed 1 November 2016, https://doi.org/10.5067/GPMGV/GCPEX/ MUTIPLE/DATA201.

Jackson, R. C., and Coauthors, 2012: The dependence of ice microphysics on aerosol concentration in arctic mixed-phase stratus clouds during ISDAC and M-PACE. J. Geophys. Res., 117, D15207, https://doi.org/10.1029/2012JD017668.

Korolev, A. V., and P. R. Field, 2015: Assessment of the performance of the inter-arrival time algorithm to identify ice shattering artifacts in cloud particle probe measurements. Atmos. Meas. Tech., 8, 761-777, https://doi.org/10.5194/amt-8-761-2015.

J. W. Strapp, G. A. Isaac, and A. N. Nevzorov, 1998: The Nevzorov airborne hot-wire LWC-TWC probe: Principle of operation and performance characteristics. J. Atmos. Oceanic Technol., 15, 1495-1510, https://doi.org/10.1175/1520-0426(1998) 015<1495:TNAHWL $>2.0$. CO;2.

, E. F. Emery, J. W. Strapp, S. G. Cober, and G. A. Isaac, 2013: Quantification of the effects of shattering on airborne ice particle measurements. J. Atmos. Oceanic Technol., 30, 2527 2553, https://doi.org/10.1175/JTECH-D-13-00115.1.

Kumar, L. S., Y. H. Lee, and J. T. Ong, 2011: Two-parameter gamma drop size distribution models for Singapore. IEEE Trans. Geosci. Remote Sens., 49, 3371-3380, https://doi.org/10.1109/ TGRS.2011.2124464.

Kummerow, C., W. Barnes, T. Kozu, J. Shiue, and J. Simpson, 1998: The Tropical Rainfall Measuring Mission (TRMM). J. Atmos. Oceanic Technol., 15, 809-817, https://doi.org/10.1175/15200426(1998)015<0809:TTRMMT>2.0.CO;2.

Lang, S. E., W. Tao, J. Chern, D. Wu, and X. Li, 2014: Benefits of a fourth ice class in the simulated radar reflectivities of convective systems using a bulk microphysics scheme. J. Atmos. Sci., 71, 3583-3612, https://doi.org/10.1175/JAS-D-13-0330.1.

L'Ecuyer, T., W. Petersen, and D. Moiseev, 2010: Light Precipitation Validation Experiment (LPVEx). National Aeronautics and Space Administration Doc., 28 pp., https://pmm.nasa.gov/sites/ default/files/document_files/lpvex_science_plan_Jan29_2010.pdf.

Liao, L., and R. Meneghini, 2005: A study of air/space-borne dualwavelength radar for estimation of rain profiles. Adv. Atmos. Sci., 22, 841-851, https://doi.org/10.1007/BF02918684.

,-- , and A. Tokay, 2014: Uncertainties of GPM DPR rain estimates caused by DSD parameterizations. J. Appl. Meteor., 53, 2524-2537, https://doi.org/10.1175/JAMC-D-14-0003.1.

Lin, Y., R. D. Farley, and H. D. Orville, 1983: Bulk parameterization of the snow field in a cloud model. J. Climate Appl. Meteor., 22, 1065-1092, https://doi.org/10.1175/1520-0450(1983)022<1065: BPOTSF $>2.0 . \mathrm{CO} ; 2$.

Mardiana, R., T. Iguchi, and N. Takahashi, 2004: A dual-frequency rain profiling method without the use of a surface reference technique. IEEE Trans. Geosci. Remote Sens., 42, 2214-2225, https://doi.org/10.1109/TGRS.2004.834647. 
Marks, D. A., D. B. Wolff, L. D. Carey, and A. Tokay, 2011: Quality control and calibration of the dual-polarization radar at Kwajalein, RMI. J. Atmos. Oceanic Technol., 28, 181-196, https://doi.org/10.1175/2010JTECHA1462.1.

McFarquhar, G. M., M. S. Timlin, R. M. Rauber, B. F. Jewett, J. A. Grim, and D. P. Jorgensen, 2007: Vertical variability of cloud hydrometeors in the stratiform region of mesoscale convective systems and bow echoes. Mon. Wea. Rev., 135, 34053428, https://doi.org/10.1175/MWR3444.1.

_- J. Um, and R. Jackson, 2013: Small cloud particle shapes in mixed-phase clouds. J. Appl. Meteor. Climatol., 52, 1277-1293, https://doi.org/10.1175/JAMC-D-12-0114.1.

, T. Hsieh, M. Freer, J. Mascio, and B. F. Jewett, 2015: The characterization of ice hydrometeor gamma size distributions as volumes in $N_{0}-\lambda-\mu$ phase space: Implications for microphysical process modeling. J. Atmos. Sci., 72, 892-909, https:// doi.org/10.1175/JAS-D-14-0011.1.

—_ and Coauthors, 2017: Processing of ice cloud in situ data collected by bulk water, scattering, and imaging probes: Fundamentals, uncertainties, and efforts toward consistency. Ice Formation and Evolution in Clouds and Precipitation: Measurement and Modeling Challenges, Meteor. Monogr., No. 58, Amer. Meteor. Soc., https://doi.org/10.1175/ AMSMONOGRAPHS-D-16-0007.1.

Meneghini, R., T. Kozu, H. Kumagai, and W. C. Boncyk, 1992: A study of rain estimation methods from space using dualwavelength radar measurements at near-nadir incidence over ocean. J. Atmos. Oceanic Technol., 9, 364-382, https://doi.org/ 10.1175/1520-0426(1992)009<0364:ASOREM>2.0.CO;2.

Meyers, M. P., R. L. Walko, J. Y. Harrington, and W. R. Cotton, 1997: New RAMS cloud microphysics. Part II: The two-moment scheme. Atmos. Res., 45, 3-39, https://doi.org/10.1016/S01698095(97)00018-5.

Milbrandt, J. A., and M. K. Yau, 2005: A multimoment bulk microphysics parameterization. Part I: Analysis of the role of the spectral shape parameter. J. Atmos. Sci., 62, 3051-3064, https://doi.org/10.1175/JAS3534.1.

Mitchell, D. L., 1996: Use of mass- and area-dimensional power laws for determining precipitation particle terminal velocities. J. Atmos. Sci., 53, 1710-1723, https://doi.org/10.1175/15200469(1996)053<1710:UOMAAD>2.0.CO;2.

__, R. Zhang, and R. L. Pitter, 1990: Mass-dimensional relationships for ice particles and the influence of riming on snowfall rates. J. Appl. Meteor., 29, 153-163, https://doi.org/10.1175/15200450(1990)029<0153:MDRFIP > 2.0.CO;2.

Moisseev, D. N., and V. Chandrasekar, 2007: Examination of the $\mu-\lambda$ relation suggested for drop size distribution parameter. J. Atmos. Oceanic Technol., 24, 847-855, https://doi.org/10.1175/ JTECH2010.1.

Morrison, H., and J. A. Milbrandt, 2015: Parameterization of cloud microphysics based on the prediction of bulk ice particle properties. Part I: Scheme description and idealized tests. J. Atmos. Sci., 72, 287-311, https://doi.org/ 10.1175/JAS-D-14-0065.1.

—_, G. Thompson, and V. Tatarskii, 2009: Impact of cloud microphysics on the development of trailing stratiform precipitation in a simulated squall line: Comparison of one- and two-moment schemes. Mon. Wea. Rev., 137, 9911007, https://doi.org/10.1175/2008MWR2556.1.

Munchak, S. J., and A. Tokay, 2008: Retrieval of raindrop size distribution from simulated dual-frequency radar measurements. J. Appl. Meteor. Climatol., 47, 223-239, https://doi.org/ 10.1175/2007JAMC1524.1.
Naeger, A. R., B. A. Colle, and A. Molthan, 2017: Evaluation of cloud microphysical schemes for a warm frontal snowband during the GPM Cold Season Precipitation Experiment (GCPEx). Mon. Wea. Rev., 145, 4627-4650, https://doi.org/ 10.1175/MWR-D-17-0081.1.

Petersen, W., and M. Schwaller, 2008: Global precipitation mission (GPM) ground validation science implementation plan. National Aeronautics and Space Administration Doc., 41 pp., https://pmm.nasa.gov/sites/default/files/document_files/ GPM_GVS_imp_plan_Jul08.pdf.

Seto, S., T. Iguchi, and T. Oki, 2013: The basic performance of a precipitation retrieval algorithm for the global precipitation measurement mission's single/dual-frequency radar measurements. IEEE Trans. Geosci. Remote Sens., 51, 5239-5251, https://doi.org/10.1109/TGRS.2012.2231686.

Skofronick-Jackson, G., and Coauthors, 2015: Global Precipitation Measurement Cold Season Precipitation Experiment (GCPEX): For measurement's sake, let it snow. Bull. Amer. Meteor. Soc., 96, 1719-1741, https://doi.org/10.1175/BAMS-D-13-00262.1.

_ , and Coauthors, 2017: The Global Precipitation Measurement (GPM) Mission for science and society. Bull. Amer. Meteor. Soc., 98, 1679-1695, https://doi.org/10.1175/BAMS-D-15-00306.1.

Tang, G., Y. Wen, J. Gao, D. Long, Y. Ma, W. Wan, and Y. Hong, 2017: Similarities and differences between three coexisting spaceborne radars in global rainfall and snowfall estimation. Water Resour. Res., 53, 3835-3853, https://doi.org/10.1002/2016WR019961.

Testud, J., S. Oury, R. A. Black, P. Amayenc, and X. Dou, 2001: The concept of "normalized" distribution to describe the raindrop spectra: A tool for cloud physics and remote sensing. J. Appl. Meteor., 40, 1118-1140, https://doi.org/10.1175/15200450(2001)040<1118:TCONDT>2.0.CO;2.

Thompson, G., P. R. Field, R. M. Rasmussen, and W. D. Hall, 2008: Explicit forecasts of winter precipitation using an improved bulk microphysics scheme. Part II: Implementation of a new snow parameterization. Mon. Wea. Rev., 136, 5095-5115, https://doi.org/10.1175/2008MWR2387.1.

Toyoshima, K., H. Masunaga, and F. A. Furuzawa, 2015: Early evaluation of Ku- and Ka-band sensitivities for the Global Precipitation Measurement (GPM) Dual-Frequency Precipitation Radar (DPR). SOLA , 11, 14-17, https://doi.org/10.2151/sola.2015-004.

Ulbrich, C., 1983: Natural variations in the analytical form of the raindrop size distribution. J. Climate Appl. Meteor., 22, 1764-1775, https:// doi.org/10.1175/1520-0450(1983)022<1764:NVITAF >2.0.CO;2.

Williams, C. R., and Coauthors, 2014: Describing the shape of raindrop size distributions using uncorrelated raindrop mass spectrum parameters. J. Appl. Meteor. Climatol., 53, 1282-1296, https://doi.org/10.1175/JAMC-D-13-076.1.

Wu, W., and G. M. McFarquhar, 2018: Statistical theory on the functional form of cloud particle size distributions. J. Atmos. Sci., 75, 2801-2814, https://doi.org/10.1175/JAS-D-17-0164.1.

Zhang, G., J. Vivekanandan, and E. A. Brandes, 2001: A method for estimating rain rate and drop size distribution from polarimetric radar measurements. IEEE Trans. Geosci. Remote Sens., 39, 830-841, https://doi.org/10.1109/36.917906.

$-,-\longrightarrow,-$, R. Meneghini, and R. Kozu, 2003: The shapeslope relation in observed gamma raindrop size distributions: Statistical error or useful information? J. Atmos. Oceanic Technol., 20, 1106-1119, https://doi.org/10.1175/1520-0426(2003)020<1106: TSRIOG $>2.0 . \mathrm{CO} ; 2$.

_ J. Sun, and E. A. Brandes, 2006: Improving parameterization of rain microphysics with disdrometer and radar observations. J. Atmos. Sci., 63, 1273-1290, https://doi.org/10.1175/JAS3680.1. 